 \\ Clinical Research andTherapeutics \\ Mary Ann Liebert, Inc. publishers
}

\section{Testosterone Therapy for Prevention and Treatment of Obesity in Men}

\author{
Monica Caliber ${ }^{1-3}$ and Farid Saad ${ }^{4-6, *}$
}

\begin{abstract}
Testosterone deficiency (TD) is common in men with obesity. The association between TD and obesity is bidirectional; low testosterone ( $T$ ) is a contributing cause to obesity, and obesity is a contributing cause to low T, creating a vicious circle. Most guidelines recommend weight loss by diet/exercise as the first point of intervention to stop this vicious cycle. However, it requires a large amount of weight loss that is maintained over time. In clinical practice, this is rarely achieved by lifestyle interventions. Bariatric surgery is currently the main obesity treatment modality that results in a large amount of weight loss with decent weight loss maintenance. However, bariatric surgery is an invasive and expensive procedure, with risk for complications. Considering the high prevalence of TD in men with obesity, a more practical and sustainable obesity treatment for men is testosterone therapy (TTh). Thanks to the metabolic effects of $\mathrm{T}$, TTh results in more fat loss and preservation of fatfree mass, compared with diet/exercise interventions alone. In contrast to weight loss achieved by diet/exercise and bariatric surgery, Th significantly preserves both muscle and bone mass. Further, Th has psychological effects that may increase the motivation and ability of men to adhere to diet/exercise programs. Real-world evidence studies of long-term TTh for up to 11 years provide compelling evidence that Th holds tremendous potential as a new treatment modality for obesity in men, with long-term weight loss maintenance and health benefits far exceeding those achieved by lifestyle interventions, approved obesity drugs, as well as bariatric surgery.
\end{abstract}

Keywords: obesity; testosterone deficiency; testosterone therapy; weight loss; body fat; fat loss; lean mass; muscle; body composition; type 2 diabetes; myocardial infarction; stroke; mortality

\section{Introduction}

The prevalence and disease burden of obesity continues to rise worldwide. ${ }^{1-4}$ Among men, $40 \%$ have obesity. ${ }^{5}$ Importantly, waist circumference (WC) in men is increasing more rapidly than body weight and body mass index (BMI). ${ }^{6}$ Although both general and abdominal obesity are associated with an increased risk of premature mortality, ${ }^{7}$ it has been shown that ab- dominal obesity may be a stronger risk factor for mortality than BMI. ${ }^{8-11}$

Cardiovascular disease (CVD), diabetes, and kidney disease are among the leading causes of obesity-related death and disability-adjusted life years (DALYs, a measure of overall disease burden, expressed as the number of years lost due to ill health or disability). ${ }^{2}$ Developed countries are facing a public health crisis related to

\footnotetext{
${ }^{1}$ Medical Writer, Fort Lauderdale, Florida, USA.

${ }^{2}$ American Medical Writers Association (AMWA), Rockville, Maryland, USA.

${ }^{3}$ International Society for Medical Publication Professionals (ISMPP), Tarrytown, New York, USA.

${ }^{4}$ Medical Affairs Consultant, Hamburg, Germany.

${ }^{5}$ Research Department, Gulf Medical University, Ajman, United Arab Emirates.

${ }^{6}$ Dresden International University, Center of Medicine and Health Sciences, Dresden, Germany.

*Address correspondence to: Farid Saad, DVM, PhD, Medical Affairs Consultant, Hinsbleek 1, 22391 Hamburg, Germany, Email: farid.saad@bayer.com
}

() Monica Caliber and Farid Saad, 2020; Published by Mary Ann Liebert, Inc. This Open Access article is distributed under the terms of the Creative Commons License (http://creativecommons.org/licenses/by/4.0), which permits unrestricted use, distribution, and reproduction in any medium, provided the original work is properly cited. 
overweight and obesity, which has likely been a key driver of the reversal of the decline in CVD mortality rates in these countries. ${ }^{12}$ In particular, the finding that overweight and obesity are affecting CVD mortality in younger age cohorts where lifetime exposure to obesity has been much shorter than in older cohorts are very concerning and are likely to adversely impact CVD mortality trends and hence life expectancy in future. $^{12}$

A large meta-analysis of prospective studies in four continents showed that men with obesity had three times the death rate than women with obesity. ${ }^{1}$ This is consistent with previous observations that, at equivalent BMI levels, men have greater insulin resistance, ectopic (e.g., liver) fat mass, and prevalence of type 2 diabetes mellitus (T2DM). ${ }^{13}$ The greater obesityrelated disease burden in men was confirmed in a recent analysis of the Global Burden of Disease Study, which showed that global deaths and DALYs attributable to obesity are significantly higher in men than women (aged $<70$ years old). ${ }^{14}$

The aim of this review is to summarize evidence regarding the need for sex-specific interventions to treat obesity in men, focusing on the link between obesity and testosterone deficiency (TD) and the clinical utility of long-term testosterone therapy (TTh) as a treatment for obesity in men.

\section{The Need for Sex-Specific Interventions to Treat Obesity in Men}

The influence of sex hormones on metabolism and regulation of energy balance, body composition, body fat distribution, and appetite is well established. ${ }^{15}$ Sex has emerged as a significant predictive factor in the development of CVD associated with metabolic dysregulation, such as obesity. ${ }^{16}$ Even though the prevalence of obesity (BMI $\geq 30 \mathrm{~kg} / \mathrm{m}^{2}$ ) is slightly higher in women than men, men suffer from more obesityrelated comorbidities and are at a higher risk of obesity-related premature death. , $^{17-19}$

A study that investigated patterns of weight regain among men and women during a long-term followup found that men have poorer weight loss maintenance than women. ${ }^{20}$ The Look Action for Health in Diabetes (AHEAD) trial likewise found sex differences in response to an intensive lifestyle intervention (ILI); although both men and women lost body fat and lean mass compared with the control group at year 1 , by year 8 , men in the ILI group had regained all body fat but not the lost lean mass, so that there was no dif- ference in body fat but a significantly reduced lean mass compared with the control group at study end. In contrast, women in the ILI group had a significantly reduced amount of body fat but no difference in lean body mass compared with the control group at year $8 .^{21}$

Sex-specific activation of the androgen receptor in the hypothalamus, skeletal muscle, liver, adipose tissue, and pancreatic islet $\beta$ cells accounts for maintenance or disruption (in the case of TD) in energy metabolism and glucose homeostasis in men. ${ }^{22}$ Therefore, the androgen receptor is a logical target for obesity interventions in men. However, there is a paucity of clinical trials examining sex-specific interventions and outcomes of obesity treatments (lifestyle-based or pharmacological). ${ }^{15}$ The study of sex differences in obesity and regulation of energy expenditure, appetite, and body composition is an area rich with clinical research opportunities. As countries around the world struggle to deal with increasing population obesity, it will be important to focus on sex differences when designing obesity interventions to achieve improved health and economic outcomes. ${ }^{15}$

There are also psychological differences between men and women, which have implications for obesity treatments. For instance, it seems that men have more difficulty perceiving they have obesity, because of the desire to be muscular and have the masculinity of a large body size. ${ }^{23}$ Unsurprisingly, a key motivator for men to start a weight loss treatment is an actual diagnosis of obesity, as opposed to simply being overweight. ${ }^{23}$ Men from various cultures reported that being overweight did not concern them, and in some cases represented an ideal weight, as they did not want to be "too thin." ${ }^{\text {"23 }}$ Further, men are more reluctant than women to undergo strict diets, and prefer to attend "men-only" treatments. ${ }^{23}$ Effective obesity interventions for men, therefore, need to frame messages that are suited to the male mindset and appeal to the masculinity ideal. One male-specific benefit of weight loss is reduction in erectile dysfunction (ED). ${ }^{24}$ The ability to perform sexually can, in turn, boost men's self-confidence and motivation to adhere to weight loss programs. Therefore, obesity interventions in men should not only focus on weight loss; they should also place greater emphasis on boosting sexual function/ performance, and pleasure will likely provide far better adherence and sustained health outcomes.

As explained in the remaining sections of this review, long-term TTh qualifies as a highly effective treatment for obesity, resulting in marked weight loss/body 
fat reduction even without dietary restriction, and preservation of lean (muscle) mass. Being well known as the "male sex hormone," TTh is obviously a "men only" treatment. With its well-documented effects on muscle gain and sex drive/function, TTh is uniquely positioned to appeal to the masculine desires of men, while curbing an epidemic public health threat.

\section{Obesity (BMI $\geq 30 \mathrm{~kg} / \mathrm{m}^{2}$ ) Versus Abdominal Obesity (WC $\geq 94 \mathrm{~cm}$ )}

Clinical guidelines diagnose obesity as BMI $\geq 30 \mathrm{~kg} / \mathrm{m}^{2}{ }^{25-27}$ This is problematic for several reasons. BMI does not distinguish between body fat mass and muscle mass, which have an opposite impact on health outcomes. In addition, BMI does not provide information about abdominal obesity, which is a greater risk factor for premature atherosclerosis, heart disease, and mortality than overall obesity. ${ }^{28}$ It is, therefore, alarming that the prevalence of abdominal obesity in the NHANES III survey is exceeding that of BMIdefined obesity $\left(\geq 30 \mathrm{~kg} / \mathrm{m}^{2}\right){ }^{29}$

The WC is the most common measure of abdominal obesity. For Caucasian/Europid populations, medical organizations recommend the WC thresholds of $\geq 94 \mathrm{~cm}$ (37 inches) in men and $\geq 80 \mathrm{~cm}$ ( 31 inches) in women for diagnosing abdominal obesity. ${ }^{30}$ Waist size typically increases with increasing body weight, whereas abdominal obesity can occur even in normal weight (BMI 18.5 to 24.9 ) people. $^{31}$ In fact, the prevalence of normal weight abdominal obesity is increasing, now affecting at least one in three adults. ${ }^{32}$

The WC is more strongly associated with allcause $^{7,9,11,33}$ and heart disease mortality ${ }^{33,34}$ than BMI. Importantly, abdominal obesity is associated with higher mortality risk, independent of BMI. ${ }^{8-11}$ For any given BMI category, apparently healthy individuals with a larger WC have an increased risk of premature mortality compared with those with a smaller WC. ${ }^{8-11}$ Even among individuals with normal weight, abdominal obesity is associated with higher mortality than BMI-defined obesity. ${ }^{31}$ Therefore, when interpreting outcomes of TTh studies, changes in WC are more clinically meaningful than changes in body weight (BMI).

\section{Bidirectional Link Between Obesity and TD}

It is well documented that the association between obesity and TD is bidirectional. ${ }^{35,36}$ Obesity is the most common and strongest risk factor for TD, more so than aging itself (as explained below). ${ }^{37-40}$
Meta-analysis evidence that obesity is a cause of TD comes from studies of weight loss (induced by either low-calorie dieting or bariatric surgery) that show that increases in $\mathrm{T}$ levels are proportional to the amount of weight lost. ${ }^{41}$ However, it should be pointed out that a large degree of sustained weight loss is required to elevate $T$ levels that are enough to be of clinical significance. In men with TD, diet-associated weight loss leads to modest increases in T, $2.87 \mathrm{nmol} / \mathrm{L}$ $(83 \mathrm{mg} / \mathrm{dL})$ with $10 \%$ loss of body weight. ${ }^{41}$ Bariatric surgery (30\% loss of body weight) is associated with a more marked increase in total T of $8.73 \mathrm{nmol} / \mathrm{L}(252 \mathrm{mg} / \mathrm{dL}),{ }^{42}$ and it has been suggested that this may contribute to the health benefits seen in men after bariatric surgery. ${ }^{41}$

A Mendelian randomization analysis confirmed the causal effect of BMI on serum $\mathrm{T}$ in men; weight loss resulting in a reduction of BMI from 30 to $25 \mathrm{~kg} / \mathrm{m}^{2}$ was estimated to correspond to a $13 \%$ increase in serum $\mathrm{T}^{43}$ Similar results were found in the prospective Massachusetts Male Aging Study (MMAS). ${ }^{37}$ Although normalization of $\mathrm{T}$ levels is a possible mechanism contributing to the beneficial health effect of bariatric surgery in excessive obesity, the increase in endogenous $\mathrm{T}$ levels with nonsurgical weight loss interventions is minor and of questionable clinical significance. Support for this comes from a randomized controlled trial (RCT) of TTh plus diet in men with obesity; a rigorous diet program leading to $11 \mathrm{~kg}(24 \mathrm{lb})$ weight loss in the placebo group increased serum $\mathrm{T}$ by only $2.9 \mathrm{nmol} / \mathrm{L}$ $(84 \mathrm{mg} / \mathrm{dL}) .{ }^{44}$ Not surprisingly, there was no improvement of hypogonadal symptoms, ${ }^{45}$ and this effect was not sustained 18 months after the trial. ${ }^{46}$

These data suggest that although obesity is a strong cause of TD, efforts to treat TD by typical diet/exercise weight loss interventions are futile.

There is also solid evidence supporting the reverse direction that low $\mathrm{T}$ is a causal contributor to development of obesity. Experimental induction of hypogonadism in healthy men aged $20-50$ years significantly increases body fat mass already after 12 weeks ${ }^{47}$ and 16 weeks, ${ }^{48}$ and men with prostate cancer (PCa) receiving androgen deprivation therapy show marked increases in total body fat mass and abdominal visceral fat within 6 months. ${ }^{49}$ A prospective study of 3351 community-dwelling men showed that men with low $\mathrm{T}$ had higher BMI, WC, and risk of metabolic syndrome (MetS) after a 10-year follow-up. ${ }^{50}$ Interestingly, men with higher baseline $\mathrm{T}$ levels not only had the lowest BMI, WC, and risk of MetS, but they also had the lowest risk of incident CVD 
events—irrespective of physical activity level—and had the lowest risk of dying from CVD. ${ }^{50}$ Low $\mathrm{T}$ is a particularly strong predictor of the development of central adiposity $^{51}$ with visceral fat accumulation. ${ }^{52}$ Another prospective study specifically examined the association between baseline $\mathrm{T}$ levels and visceral fat accumulation (measured by computed tomography) after a follow-up of 7.5 years. ${ }^{52}$ Men with low T at baseline had a significantly greater increase in visceral fat, even after adjustment for baseline visceral and subcutaneous fat mass, BMI, age, T2DM status (oral glucose tolerance test by the World Health Organization diagnostic criteria), and fasting C-peptide. ${ }^{52} \mathrm{~A}$ real-world evidence (RWE) study of men with TD and various body weight categories investigated the effect of long-term TTh for up to 11 years. ${ }^{42}$ All men in the control group, regardless of baseline weight status, experienced a marked increase in body weight and WC. ${ }^{42}$ Importantly, the greatest increases in body weight and WC occurred after 6 years in men with normal weight and overweight at baseline. As expected, $\mathrm{T}$ levels significantly declined over time, from 9.5 to $8.5 \mathrm{nmol} / \mathrm{L}$ in the normal weight, from 9.6 to $8.2 \mathrm{nmol} / \mathrm{L}$ in the overweight, and from 9.8 to 7.7 in the obese groups, respectively. ${ }^{42}$ This suggests that the causal role of TD in the development of obesity takes multiple years to fully manifest.

Further proof of the causal role of TD in the pathogenesis of obesity comes from a growing number of studies showing that TTh significantly reduces markers of obesity (including body weight, WC, waist-to-height ratio, and $\mathrm{BMI}),{ }^{42,53-55}$ total body fat mass, ${ }^{47,48,56-61}$ and intra-abdominal fat mass. ${ }^{61-64}$ The remaining sections in this review will summarize important studies regarding the potential use of TTh as a treatment for obesity in men with TD.

\section{Obesity Is More Strongly Linked to Low Testosterone than Age}

A common misperception is that advancing age is the main cause of TD. Although the prevalence of TD increases with advancing age, this is mainly due to comorbidities-particularly obesity and T2DMrather than aging per se. ${ }^{37,65-72}$ As a consequence of the growing obesity epidemic among all age groups, the prevalence of TD in young men is increasing. ${ }^{73} \mathrm{~A}$ meta-analysis of 18 studies (comprising a total of 4546 men with obesity, age ranging from 27.9 to 61.9 years, and BMI ranging from 24.8 to $50.3 \mathrm{~kg} / \mathrm{m}^{2}$ ) found a TD prevalence as high as $50-80 \%{ }^{74}$ Studies using total $\mathrm{T}$ and free $\mathrm{T}$ showed the same trend of increasing prevalence of TD with increasing BMI. ${ }^{74}$

The Coronary Artery Risk Development in Young Adults (CARDIA) study showed that increasing obesity, particularly abdominal obesity, is associated with decreasing $\mathrm{T}$ levels in young men aged $18-30$ years. ${ }^{75,76}$

A report from the Centers for Disease Control showed that among men, the prevalence of obesity was $40.3 \%$ in those aged $20-39,46.4 \%$ among those aged $40-59$, and $42.2 \%$ among those aged 60 and older. ${ }^{73}$ In other words, obesity is nearly as common in younger men as in older men. Not surprisingly, up to $33-58 \%$ of young men (age 35 years or younger) with obesity have TD. ${ }^{77-79}$ Another study found that among young men (aged 33-45 years) with obesity attending primary care, the prevalence of TD was as high as up to $75 \%{ }^{80}$ This is similar to the TD prevalence seen in older men with obesity. ${ }^{81-84}$

The MMAS showed that an increase in BMI of $4-5 \mathrm{~kg} / \mathrm{m}^{2}$ was associated with a reduction in $\mathrm{T}$ levels comparable to that seen during $\sim 10$ years of aging in men whose body weight remained unchanged. ${ }^{37}$ In the European Male Aging Study (EMAS), obese men $\left(\mathrm{BMI} \geq 30 \mathrm{~kg} / \mathrm{m}^{2}\right)$ had a $30 \%$ lower T level-equivalent to almost three decades of aging-and a 13-fold increase in TD prevalence compared with men with a BMI of $<25 \mathrm{~kg} / \mathrm{m}^{2}{ }^{38,39}$ Prospective data from EMAS showed that a $10 \%$ weight gain $(+12.3 \mathrm{~kg})$ and $10 \%$ weight loss $(-13.7 \mathrm{~kg})$ was associated with a proportional decrease $(-2.4 \mathrm{nmol} / \mathrm{L})$ and increase $(+2.9 \mathrm{nmol} / \mathrm{L})$ in T levels during a 4-year follow-up, respectively. ${ }^{40}$ Obesity is associated with low $\mathrm{T}$ levels even in young men aged 24-41 years, a finding that supports the notion that obesity is a stronger risk factor for TD than age itself. ${ }^{75}$

Facing the current epidemic of obesity, it is critical for health care professionals to know that body fatness is more strongly associated with low $\mathrm{T}$ levels than age. $^{29,72,85}$ Therefore, $\mathrm{T}$ levels should be measured in men with excess body fat and/or large waist size, regardless of age, and TTh should be offered to all men who have no contraindications. ${ }^{26}$

\section{Clinical Utility of TTh as a Treatment for Obesity: Long-Term RWE}

The RWE from long-term observational studies have provided compelling support for the use of TTh as a sustainable and feasible treatment for obesity. ${ }^{42,53-55,86-93}$ These observational studies comprise men with TD and various degrees of obesity and weight classes, ranging from normal weight to obesity class III, 
who are receiving long-term treatment with $\mathrm{T}$ undecanoate injections in real-life urology practices.

Because the health benefits of TTh are time dependent, these RWE studies provide valuable data about the true clinical significance of TTh, which cannot be derived from RCTs due to their short-term nature. The longest duration TTh RCTs are 3 years. In contrast, RWE data on metabolic/sexual, skeletal, and prostate outcomes have been continuously collected for 12 years, ${ }^{93} 6$ years, ${ }^{94}$ and 17 years, ${ }^{95}$ respectively.

One RWE study examined the effects of long-term TTh on anthropometric and metabolic parameters in 411 men with TD (mean age 60 years) and different degrees of obesity: class I (BMI $30-34.9 \mathrm{~kg} / \mathrm{m}^{2} ; n=214$ ), class II (BMI $\left.35-39.9 \mathrm{~kg} / \mathrm{m}^{2} ; n=150\right)$, and class III $\left(\mathrm{BMI} \geq 40 \mathrm{~kg} / \mathrm{m}^{2} ; n=47\right)$. TTh was given as T undecanoate injections in 12 weeks intervals for up to 8 years. ${ }^{55}$ In all three classes of obesity, TTh resulted in significant weight loss and a decrease in WC and BMI (Table 1). In men with class I and class II obesity, BMI dropped to below $30 \mathrm{~kg} / \mathrm{m}^{2}$, hence moving men from the obese state to the overweight state (Table 1). ${ }^{55}$

In a 10-year follow-up of 115 patients who had been continuously treated with $\mathrm{T}$ undecanoate injections, BMI decreased from 31 to $27 \mathrm{~kg} / \mathrm{m}^{2}$. The decrease was significant versus baseline $(p<0.0001)$ and significant versus previous year for the first 8 years. ${ }^{87}$ Body weight decreased from 97.3 to $84.6 \mathrm{~kg}$. The weight loss was progressive and reached $18.5 \%$ (range $6.19 \%$ to $31.97 \%$ ) after 10 years. At baseline, nearly all men (97.4\%) had an elevated WC $(\geq 94 \mathrm{~cm})$, out of which $67 \%$ had a substantially elevated WC $(\geq 102 \mathrm{~cm})$. Mean WC decreased progressively from 106.5 to $92.3 \mathrm{~cm}$ $(12 \%)$. The decrease was significant versus baseline $(p<0.0001)$ and significant versus previous year for the first 7 years. ${ }^{87}$
Interestingly, men with moderate-to-severe ED or lower urinary tract symptoms have a more severe cardiovascular $(\mathrm{CV})$ risk profile and benefit more from TTh than men with mild symptoms. ${ }^{91,93}$ In men with obesity and various degrees of $\mathrm{ED}$, treatment with $\mathrm{T}$ undecanoate injections for up to 12 years reduced body weight by $\sim 18 \mathrm{~kg}(-16 \%)$, WC by $10 \mathrm{~cm}$, and BMI by $6 \mathrm{~kg} / \mathrm{m}^{2}$ (from 33 to $27 \mathrm{~kg} / \mathrm{m}^{2}$ ). ${ }^{93}$ Considering the high prevalence of ED in men with obesity, it is remarkable that erectile function continued to significantly improve for each successive year for 9 years. ${ }^{93}$

A more recent analysis of RWE data examined the effect of TTh for up to 11 years in men $(n=823)$ with various weight classes. ${ }^{42}$ Of these men, 474 (57.6\%) had obesity, 286 (34.8\%) overweight, and 63 (7.7\%) normal weight. In 428 men (281 with obesity, 121 with overweight, and 26 with normal weight), $\mathrm{T}$ undecanoate $1000 \mathrm{mg}$ injections were administered every 12 weeks after an initial 6-week interval, for up to 11 years. The remaining 395 men served as a control group. Anthropometric and metabolic parameters were measured at least twice yearly, and changes were adjusted for confounding factors to account for baseline differences between groups. In the normal weight group, $\mathrm{T}$ treated men had a weight loss of $-3.4 \mathrm{~kg}$ $(-4.8 \%)$, whereas untreated men had a weight gain of $6.1 \mathrm{~kg}(+8 \%)$. In the overweight group, T-treated men had a weight loss of $-8.5 \mathrm{~kg}(-9.6 \%)$, whereas untreated men had a weight gain of $6.0 \mathrm{~kg}(+6.9 \%)$. In the obese group, T-treated men had a weight loss of $-23.2 \mathrm{~kg}(-20.6 \%)$, whereas untreated men had a weight gain of $4.2 \mathrm{~kg}(+5.1 \%)$. Corresponding changes were seen in WC and BMI. The WC decreased in T-treated men (increased in untreated men) by $-3.4 \mathrm{~cm}(+5.6 \mathrm{~cm}),-4.7 \mathrm{~cm}(+5.5 \mathrm{~cm})$, and $-12.9 \mathrm{~cm}$ $(+5.6 \mathrm{~cm})$ in the normal weight, overweight, and

Table 1. Changes in Obesity Parameters After Testosterone Therapy for up to 8 Years

\begin{tabular}{|c|c|c|c|}
\hline & $\begin{array}{l}\text { Class I obesity } \\
\text { BMI } 30-34.9\end{array}$ & $\begin{array}{c}\text { Class II obesity } \\
\text { 35-39.9 }\end{array}$ & $\begin{array}{l}\text { Class III obesity } \\
\text { BMI } \geq 40\end{array}$ \\
\hline Total testosterone & $\begin{array}{l}+8.16 \mathrm{nmol} / \mathrm{L} \text { (from } 8.74 \\
\left.\text { to } 17.02^{\mathrm{a}} \mathrm{nmol} / \mathrm{L}\right)\end{array}$ & $\begin{array}{l}+7.29 \mathrm{nmol} / \mathrm{L} \\
\quad\left(\text { from } 9.3 \text { to } 16.86^{\mathrm{a}} \mathrm{nmol} / \mathrm{L}\right)\end{array}$ & $\begin{array}{l}+6.41 \mathrm{nmol} / \mathrm{L} \text { (from } 9.34 \\
\left.\text { to } 15.99^{\mathrm{a}} \mathrm{nmol} / \mathrm{L}\right)\end{array}$ \\
\hline $\begin{array}{l}\text { Free testosterone } \\
\text { Body weight }\end{array}$ & $\begin{array}{l}+235 \mathrm{ng} / \mathrm{dL} \text { (from } 252 \text { to } 491^{\mathrm{a}} \mathrm{ng} / \mathrm{dL} \text { ) } \\
-17.4 \mathrm{~kg} \text { or }-16.8 \% \text { (from } 102.6 \mathrm{~kg} \\
\quad \text { to } 84.1 \mathrm{~kg} \text { ) }\end{array}$ & $\begin{array}{l}+210 \mathrm{ng} / \mathrm{dL} \text { (from } 268 \text { to } 486^{\mathrm{a}} \mathrm{ng} / \mathrm{dL} \text { ) } \\
-25.3 \mathrm{~kg} \text { or }-21.5 \% \text { (from } 116.8 \\
\text { to } 91.3 \mathrm{~kg} \text { ) }\end{array}$ & $\begin{array}{l}+185 \mathrm{ng} / \mathrm{dL} \text { (from } 269 \text { to } 461^{\mathrm{a}} \mathrm{ng} / \mathrm{dL} \text { ) } \\
-30.5 \mathrm{~kg} \text { or }-23.6 \% \text { (from } 129.0 \\
\text { to } 98.9 \mathrm{~kg} \text { ) }\end{array}$ \\
\hline $\begin{array}{l}\text { Waist circumference } \\
\text { BMI }\end{array}$ & $\begin{array}{l}-10.6 \mathrm{~cm} \text { (from } 106.8 \text { to } 95.1 \mathrm{~cm} \text { ) } \\
-5.52 \text { (from } 32.69 \text { to } 27.07 \text { ) }\end{array}$ & $\begin{array}{l}-13.9 \mathrm{~cm} \text { (from } 113.5 \text { to } 100.0 \mathrm{~cm} \text { ) } \\
-8.15 \text { (from } 37.32 \text { to } 29.49 \text { ) }\end{array}$ & $\begin{array}{l}-14.3 \mathrm{~cm} \text { (from } 118.5 \text { to } 103.8 \mathrm{~cm} \text { ) } \\
-9.96 \text { (from } 41.93 \text { to } 32.46 \text { ) }\end{array}$ \\
\hline
\end{tabular}

Data from: Saad et al. ${ }^{55}$

${ }^{a}$ When interpreting elevations in T levels (total and free), one has to keep in mind that these reported levels are trough levels, i.e. the lowest level measured immediately before the next injection. Trough levels can serve as an indicator of whether therapeutic $\mathrm{T}$ levels have been achieved..

BMI, body mass index. 
obese groups, respectively. The differences in percent body weight change between groups, after adjustments for confounding factors, became significant in the normal weight group after year 1 , and in the overweight and obese groups after year 2 (Fig. 1A). The differences in WC change between groups, after adjustments for confounding factors, became significant in the normal weight group after year 5 , in the overweight group after year 2 , and in the obese group after year 1 (Fig. 1B). The changes in body weight and WC were accompanied by corresponding changes in lipids and glucose control (improvement in T-treated men and worsening in untreated men).

In another RWE analysis, 316 men with prediabetes (defined as hemoglobin Alc $\left[\mathrm{HbA}_{1 \mathrm{c}}\right]$ 5.7-6.4\%) and TD (defined as total T levels $\leq 12.1 \mathrm{nmol} / \mathrm{L}$ combined with symptoms) were included. ${ }^{54}$ Of these, 229 men received $\mathrm{T}$ undecanoate injections for 8 years, and 87 men served as untreated control subjects. Metabolic and anthropometric parameters were measured twice yearly. At baseline, in both groups, $\mathrm{BMI}, \mathrm{HbA}_{1 \mathrm{c}}$, and International Index of Erectile Function, Erectile Function Domain (IIEF-EF) were $30 \mathrm{~kg} / \mathrm{m}^{2}, 5.9 \%$, and 11 , respectively. TTh led to substantial improvement in glycemic parameters, with significant reductions in fasting blood glucose and $\mathrm{HbA}_{1 \mathrm{c}}$. In contrast, in the untreated group, glycemic parameters worsened over time. At the last observation, all 229 patients (100\%) in the TTh group had an $\mathrm{HbA}_{1 \mathrm{c}}$ of $<6.5 \%(48 \mathrm{mmol} /$ mol), and 205 of these 229 patients (90\%) achieved normal glucose regulation with an $\mathrm{HbA}_{1 \mathrm{c}}<5.7 \%$ $(39 \mathrm{mmol} / \mathrm{mol})$. In the untreated group, only 1 patient (of 87, i.e., $1 \%$ ) had $\mathrm{HbA}_{1 \mathrm{c}}<5.7 \%(39 \mathrm{mmol} / \mathrm{mol}$ ) whereas 35 men $(40.2 \%)$ had progressed to frank T2DM with $\mathrm{HbA}_{1 \mathrm{c}}>6.5 \%(48 \mathrm{mmol} / \mathrm{mol}) .{ }^{54} \mathrm{Men}$ in the TTh group achieved a weight loss of $8 \%$ at 8 years, whereas untreated men experienced a weight gain of $9 \%$. This corresponded to a weight loss of $9.2 \mathrm{~kg}$ in T-treated patients and a weight gain of $8 \mathrm{~kg}$ in the untreated group. The WC decreased by $6.8 \mathrm{~cm}$ in the TTh group whereas it increased by $7.4 \mathrm{~cm}$ in the untreated group. ${ }^{54}$ This is the first study to show that long-term TTh not only completely prevents progression of prediabetes to frank T2DM but also restores normal glucose regulation in most men.

Another RWE analysis of 356 men with T2DM and TD examined whether long-term TTh can result in remission of T2DM. ${ }^{92}$ Remission of T2DM was defined as $\mathrm{HbA}_{1 \mathrm{c}}<6.5 \%$ and discontinuation of all diabetes drugs, including metformin. All patients received standard T2DM treatment. One hundred seventy-eight men additionally received treatment with $\mathrm{T}$ undecanoate injections $1000 \mathrm{mg}$ every 12 weeks after an initial 6-week interval. The remaining 178 men did not receive TTh and served as a control group. ${ }^{92}$ The T-treated men had a progressive and sustained reduction in body weight of $-22.1 \mathrm{~kg}(-19.3 \%)$ and $\mathrm{WC}$ of $-13.3 \mathrm{~cm}$. In contrast, the control group had an increase in body weight and WC of $+6.8 \mathrm{~kg}(+7.4 \%)$ and $+7.1 \mathrm{~cm}$, respectively. In parallel with the reduction in body weight and WC, T-treated men had significant progressive and sustained reductions in fasting glucose, $\mathrm{HbA}_{1 \mathrm{c}}$, and fasting insulin throughout the entire treatment period. In contrast, the control group had progressive elevations in fasting glucose, $\mathrm{HbA}_{1 \mathrm{c}}$, and fasting insulin. The T-treated men who had been on insulin at baseline had a reduction in insulin dose requirement compared with the control group, suggesting improved $\beta$ cell function. In contrast, 20 patients in the control group were started on insulin treatment during the observation time, suggesting deteriorated $\beta$ cell function. Remarkably, among T-treated men, $34.3 \%$ (61 out of 178 patients) achieved remission of T2DM (22 of these patients had been on insulin at baseline). The average time to discontinuation of diabetes medications was 8.6 years; the average time in remission was 2.5 years. There were no relapses. Overall, $46.6 \%$ of patients achieved normal glucose regulation (these patients, if not yet in remission, are eligible for discontinuation of diabetes drugs, which will be explored in an upcoming update of this ongoing study), 83.1\% reached the $\mathrm{HbA}_{1 \mathrm{c}}$ target of $6.5 \%$, and $90 \%$ reached the $\mathrm{HbA}_{1 \mathrm{c}}$ target of $7.0 \%$. In contrast, no remission of $\mathrm{T} 2 \mathrm{DM}$ or reduction in glucose or $\mathrm{HbA}_{1 \mathrm{c}}$ levels was noted in the control group. ${ }^{92}$

\section{Importance of Uninterrupted TTh and Achievement of Therapeutic Testosterone Levels}

A prerequisite for achievement of maximal metabolic and body composition benefits (loss of excess body fat with preserved or increased fat-free mass [FFM]) of TTh is long-term uninterrupted treatment. Multiple studies have shown that the beneficial effects of TTh are not maintained if treatment is discontinued. ${ }^{46,53,96-100}$ This applies not only to improvements in body composition but also to improvements in muscle strength, erectile function, $\mathrm{HbA}_{1 \mathrm{c}}$, total cholesterol, low-density lipoprotein cholesterol (LDL), high-density lipoprotein cholesterol (HDL), triglycerides, AMS, IPSS, IIEF-EF, residual voiding volume and bladder wall thickness, quality of life, and likely 


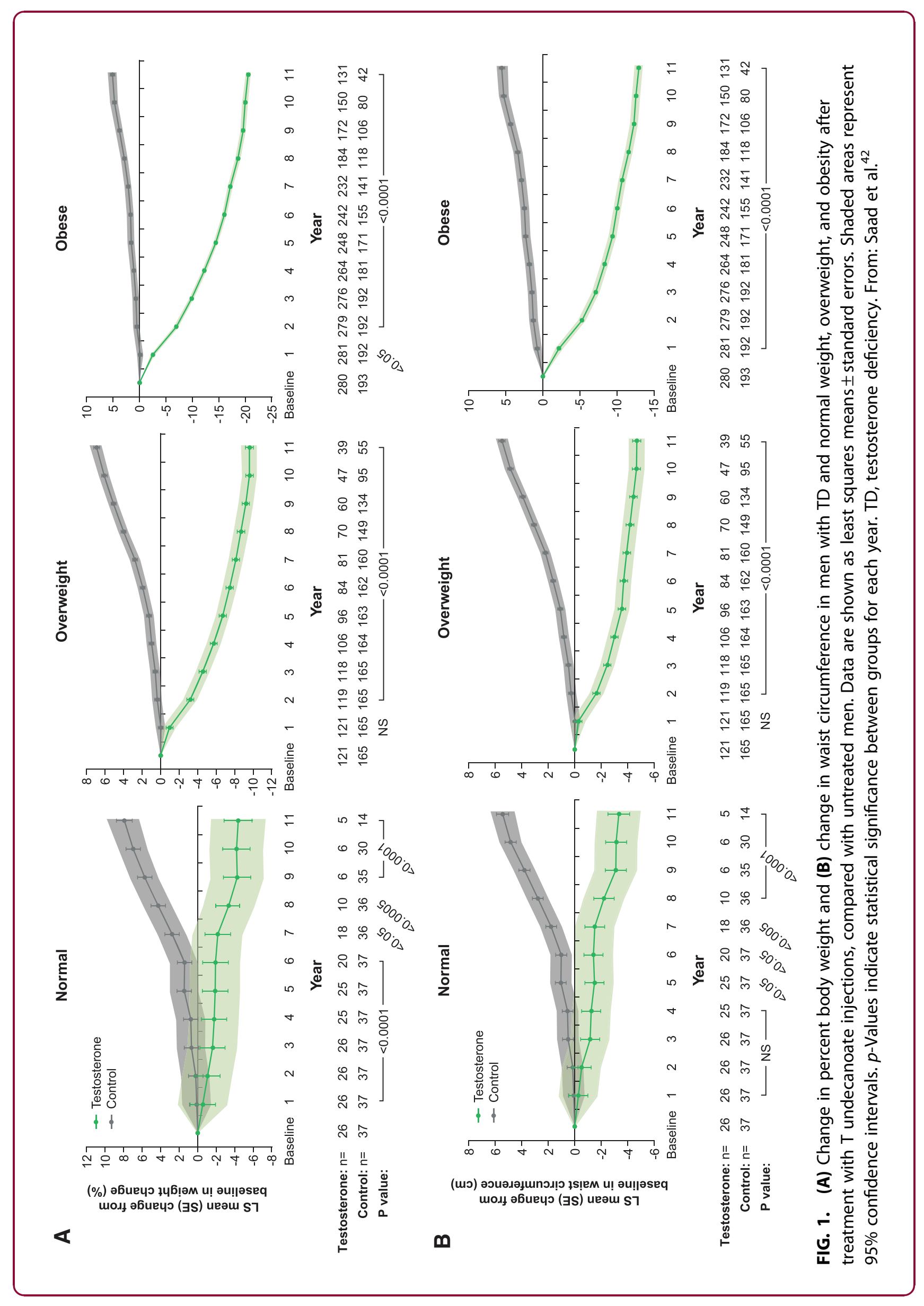


most-if not all-other T-related outcomes. ${ }^{46,53,96-100}$ Nevertheless, beneficial effects return when TTh is resumed. ${ }^{98}$ As pointed out in the British Society for Sexual Medicine guidelines on Adult Testosterone Deficiency, cessation of TTh results in progressive reappearance of symptoms and reversal of benefits (commonly within 6 months), so TTh is likely to be required lifelong for persistent symptom resolution and maintenance of health benefits. ${ }^{65}$

A related issue occurs when TTh is not properly dosed to achieve a high enough elevation of $\mathrm{T}$ levels (within the physiological range) for therapeutic efficacy. There are different $\mathrm{T}$ threshold levels for different responses to TTh; hence, TTh needs to achieve sustained therapeutic $\mathrm{T}$ levels to be effective. ${ }^{101}$

The Hormonal Regulators of Muscle and Metabolism in Aging (HORMA) Trial found that increases in total T of $1046 \mathrm{ng} / \mathrm{dL}$ (95\% confidence interval $[\mathrm{CI}]=1040$ $1051)$ and $898 \mathrm{ng} / \mathrm{dL}(95 \% \mathrm{CI}=892-904)$ were necessary to achieve median increases in lean body mass of $1.5 \mathrm{~kg}$ and appendicular skeletal muscle mass of $0.8 \mathrm{~kg}$, respectively, which, in turn, were required to significantly enhance one-repetition maximum strength. ${ }^{102}$ Therefore, for maximal benefits the dose of TTh should be titrated to achieve target $\mathrm{T}$ blood levels. ${ }^{102}$

The correlation between declining T levels during TTh and suboptimal response can be seen in several studies. For instance, in a long-term TTh study, body fat \% dropped from $31.5 \%$ at baseline to $26.5 \%$ at month $24 .{ }^{103}$ This was accompanied by an increase in total and free $\mathrm{T}$ levels from 9.1 to $19.1 \mathrm{nmol} / \mathrm{L}$ ( 263 to $551 \mathrm{ng} / \mathrm{dL}$ ) and from 6.2 to $14.3 \mathrm{ng} / \mathrm{dL}$, respectively. However, at month 96 , total and free T levels had dropped to 372 and $8.68 \mathrm{ng} / \mathrm{dL}$ respectively, with body fat \% no longer being significantly different from baseline, ${ }^{103}$ suggesting inadequate dosing/adherence to TTh. Similarly, other studies have found that men who receive TTh that fails to normalize (restore) $\mathrm{T}$ levels (due to inadequate dose or adherence) do not experience a reduction in myocardial infarction (MI), stroke, atrial fibrillation or all-cause mortality, which is seen in men who receive TTh that does normalize (restore) T levels. ${ }^{104-106}$ Suboptimal TTh also occurs in randomized controlled trials. In the Testosterone's Effects on Atherosclerosis Progression in Aging Men (TEAAM) trial, 156 men were randomized to receive TTh and 152 were randomized to receive placebo for 3 years. Despite aiming at achieving $\mathrm{T}$ levels between 500 and $900 \mathrm{ng} / \mathrm{dL}$, at 6,18 , and 36 months total $\mathrm{T}$ levels were $\sim 640,600$, and $460 \mathrm{ng} / \mathrm{dL}$, respectively, and free $\mathrm{T}$ levels were 12,11 , and $8.5 \mathrm{ng} / \mathrm{dL}$, respectively.
Because target $\mathrm{T}$ blood levels ( $\mathrm{T}$ thresholds) likely vary between individuals, it is important to regularly monitor T levels during TTh, and in cases of suboptimal or lack of response, increase the TTh dose for a sufficient length of time and then re-evaluate. ${ }^{107,108}$ In a secondary analysis of the BLAST study, examining $\mathrm{T}$ levels associated with clinical and biochemical improvements, it was pointed out that men with severe obesity may need shorter dosing intervals of $\mathrm{T}$ undecanoate-around 10 weeks between injections as opposed to 12 weeks-to achieve ideal therapeutic T levels, especially if the target levels of $>15 \mathrm{nmol} / \mathrm{L} \mathrm{rec}-$ ommended in clinical guidelines are to be reached within 3-6 months. ${ }^{101}$

\section{TTh in Comparison to Traditional Obesity Treatments}

To fully appreciate the potential of TTh as an obesity treatment modality, it is informative to compare the weight loss and changes in body composition achieved with TTh with those achieved in traditional obesity interventions. A meta-analysis of weight loss trials reported a mean weight loss of 5 to $8.5 \mathrm{~kg}$ (5\% to 9\%) during the first 6 months from interventions with reduced-energy diets and/or weight-loss medications, with weight loss plateaus commonly occurring at $\sim 6$ months. ${ }^{109}$ A systematic review of long-term weight loss studies found that diet/lifestyle interventions result in $<5 \mathrm{~kg}$ weight loss after $2-4$ years and obesity drugs result in $5-10 \mathrm{~kg}$ weight loss after $1-2$ years. ${ }^{110}$ After completing structured weight-loss programs, subjects regained half of the lost weight after 1 year and nearly three quarter during the first three years; less than $3 \%$ of subjects maintained their weight loss at all annual visits for 4-5 years after completion of a weight-loss program. $^{20,111,112}$ Meta-analysis shows that people on average maintain a weight loss of $3 \mathrm{~kg}$ and a reduced weight of $3 \%$ of initial body weight after 5 years. ${ }^{113}$ Obesity medications approved for long-term use, when prescribed with lifestyle interventions, produce additional weight loss relative to placebo ranging from $\sim 3 \%$ to $9 \%$ of initial weight at 1 year. ${ }^{114}$ However, a major limitation of diet/exercise and obesity drug interventions is high dropout and a large proportion of subjects lost to follow-up. ${ }^{110,115}$

The Look AHEAD trial showed that an ILI resulted in a weight loss of $-6 \%$ after 4 years. ${ }^{116}$ In the RWE study of TTh in men with various severity of obesity (summarized above), weight loss at year 4 ranged from $-10 \%$ to $-15 \%$, depending on obesity grade. ${ }^{55}$ 
An 8-year analysis of The Look AHEAD trial (baseline BMI of $35 \mathrm{~kg} / \mathrm{m}^{2}$ ) reported a weight loss of 7.9, 3.7, and $4.0 \mathrm{~kg}$ for year 1,4 , and 8 , respectively. ${ }^{21}$ The corresponding weight loss in men on long-term TTh was $3,10.7$, and $17.4 \mathrm{~kg}$ in class I obese men, 3.8, 16.6, and $25.3 \mathrm{~kg}$ in class II obese men, and $3.5,18.5$, and $30.5 \mathrm{~kg}$ in class III obese men (Table 2). ${ }^{55}$

As shown in Table 2, there was a marked weight regain after the first year in the ILI. In contrast, long-term TTh resulted in a sustained and progressive weight loss, with no plateau or weight regain. After 8 years, weight loss was four- to eight-fold greater with TTh than ILI.

The Look AHEAD trial, which is the longest duration ILI with body composition data, clearly shows a marked loss of FFM. ${ }^{21}$ In a sex-specific analysis, differences in fat mass among men in the intervention and control groups were not significant at year 8; however, men in the intervention group had a significantly greater loss of FFM at all time points. ${ }^{21}$ From baseline to year 1, fat mass and FFM did not change in men in the control group, whereas men in the intervention group had a weight loss of $9.4 \mathrm{~kg}$, of which nearly $3 \mathrm{~kg}(30 \%)$ was FFM. From year 1-8, there was little change in the fat mass and FFM in the control group, and FFM in the intervention group. However, the year 1-8 weight gain in men (as well as women) in the intervention group was $\sim 100 \%$ fat mass. ${ }^{21}$

As of this writing, there is no long-term TTh trial with body composition data that included a control group. Nevertheless, body composition trials of TTh (summarized below) show that TTh results in a greater reduction in fat mass per unit weight loss (in other words, preservation of FFM) compared with diet/ exercise interventions. The large reduction in $\mathrm{WC}$ seen in the RWE studies outlined earlier confirms the

Table 2. Long-Term Weight Loss with Testosterone Therapy Compared with Intensive Lifestyle Intervention ${ }^{\mathrm{a}}$

\begin{tabular}{lccc}
\hline & $\begin{array}{c}\text { Year 1 weight } \\
\text { loss } \mathbf{( k g )}\end{array}$ & $\begin{array}{c}\text { Year } \mathbf{4} \text { weight } \\
\text { loss } \mathbf{( k g )}\end{array}$ & $\begin{array}{c}\text { Year } \mathbf{8} \text { weight } \\
\text { loss } \mathbf{( k g})\end{array}$ \\
\hline $\begin{array}{l}\text { Look AHEAD trial } \\
\text { BMI 35 }\end{array}$ & 9.4 & 5.0 & 3.0 \\
$\begin{array}{c}\text { Class I obesity } \\
\text { BMI 30-34.9 }\end{array}$ & 3.0 & 10.7 & 17.4 \\
$\begin{array}{l}\text { Class II obesity } \\
\text { 35-39.9 }\end{array}$ & 3.8 & 16.6 & 25.3 \\
$\begin{array}{l}\text { Class III obesity } \\
\text { BMI } \geq 40\end{array}$ & 3.5 & 18.5 & 30.5 \\
\hline
\end{tabular}

${ }^{\text {a }}$ References. ${ }^{21,55,116}$

Data from: Saad et al., ${ }^{55}$ and the Look AHEAD (Action for Health in Diabetes) study. ${ }^{21,116}$

AHEAD, Action for Health in Diabetes. beneficial effect of TTh on body composition and body fat distribution.

Weight loss is only one aspect of obesity treatment. Perhaps more important is the issue of weight loss maintenance. Weight-loss programs based on diet, exercise, and obesity drugs can help people lose weight, whereas maintaining weight loss seems to be the greatest challenge. ${ }^{117-119}$ Even when obesity drugs are used during the maintenance phase, the vast majority regain most of the lost weight. ${ }^{120}$ Considering that long-term TTh results in a progressive sustained reduction in obesity markers, combined with data showing that men may be more likely to regain weight after weight loss programs, ${ }^{20,121}$ TTh holds tremendous potential as a unique obesity treatment for men.

\section{TTh in Comparison to Bariatric Surgery}

Among approved obesity treatments, bariatric surgery results in the greatest long-term weight loss maintenance, ${ }^{122,123}$ with an average reduction in body weight after $2,10,15$, and 20 years in the magnitude of $-23 \%$, $-17 \%,-16 \%$, and $-18 \%$, respectively. ${ }^{122}$ A metaanalysis showed a weight-loss maintenance of $22.2 \%$ $(30.1 \mathrm{~kg}) 20$ years after bariatric surgery. ${ }^{123}$ In a multicenter longitudinal study of 2348 bariatric surgery patients, after roux-en-Y gastric bypass (RYGB) and laparoscopic adjustable gastric banding (LAGB) the 7 -year mean weight loss was $28.4 \%(-38.2 \mathrm{~kg})$ and $14.9 \%(-18.8 \mathrm{~kg})$, respectively. ${ }^{124}$ Between years 3 and 7 , there was a mean weight regain of $3.9 \%$ (RYGB) and $1.4 \%$ (LAGB). Among RYGB patients, $75 \%$ maintained at least $20 \%$ weight loss, and $50 \%$ of LAGB patients maintained at least $16 \%$ weight loss through 7 years. The remission of T2DM at year 7 was $60 \%$ for RYGB and $20.3 \%$ for LABG. ${ }^{124}$

Compared with usual care, bariatric surgery is associated with a long-term reduction in overall mortality [adjusted hazard ratio (HR) $=0.71,95 \%$ CI $0.54-0.92$; $p=0.01]$ and decreased incidence of T2DM (adjusted $\mathrm{HR}=0.17 ; p<0.001$ ), MI (adjusted HR=0.71; $p=0.02$ ), and stroke (adjusted $\mathrm{HR}=0.66 ; p=0.008) .{ }^{122}$ One study found that remission of T2DM after bariatric surgery was achieved in 58.2\% $(n=2090)$ of patients at 2 years, and in $46.6 \%$ of patients at 5 years. ${ }^{125}$ Although T2DM remission can be as high as $74 \%$ at 1 year postsurgery, T2DM relapse increased over time with a longer follow-up duration. ${ }^{125,126}$

As summarized earlier, TTh for 8 years results in weight loss corresponding to $16.8 \%$ to $23.6 \%$, depending on baseline obesity grade (Table 1 ). ${ }^{55}$ An 11-year 
analysis of RWE data showed that men who had been receiving TTh had a weight loss of $-23.2 \mathrm{~kg}(-20.6 \%)$, whereas untreated men had a weight gain of $4.2 \mathrm{~kg}$ $(+5.1 \%) .{ }^{127}$ The marked weight loss seen during longterm TTh is accompanied by a reduced incidence of $\mathrm{T}_{2} \mathrm{DM}^{54}$ and remission of $\mathrm{T} 2 \mathrm{DM}$ in $34.3 \%$ of patients. ${ }^{92}$ In an RWE analysis, the average time to discontinuation of diabetes medications (i.e., achievement of T2DM remission) was 8.6 years. ${ }^{92}$ During a followup time of 2.5 years, there were no relapses. ${ }^{92}$ Longerterm follow-up of this RWE cohort will tell whether T2DM relapse will occur. Currently, data suggest that with increasing the duration of TTh, the greater the rate of T2DM remission, that is, opposite to that seen with bariatric surgery.

As outlined later, TTh also compares favorably regarding long-term reduction in overall mortality, MI, and stroke. Although bariatric surgery results in greater short-term ( $<2$ years) weight loss and T2DM, it is an invasive and very expensive procedure. Due to its risk for complications and high cost, it is only an option for a small minority of men with obesity and will hence not help curb the global obesity epidemic.

\section{Effect of Traditional Obesity Treatments and Bariatric Surgery on Bone Mineral Density and Fractures}

In addition to loss of FFM (discussed in the next section), another negative effect of diet-based obesity intervention $^{128,129}$ and bariatric surgery is significant loss of bone mineral density (BMD). Studies of both diet-induced weight loss and bariatric surgery show changes in bone markers, reflecting an increased bone turnover, evidenced by increased urinary excretion of deoxypyridinoline and serum levels of osteocalcin. ${ }^{130}$ A 30-month follow-up study of a 1-year lifestyle intervention trial found a significant progressive reduction in total hip BMD despite lack of change in FFM or appendicular lean mass. ${ }^{131}$ Weight loss of $10 \%$ or more beginning at age 50 years increases the risk of hip fracture in older men. ${ }^{132}$ Among patients with T2DM, a weight loss of $\geq 20 \%$ is a significant risk factor for fractures, especially for men. ${ }^{133}$ The Osteoporotic Fractures in Men (MrOS) study demonstrated that the impact of weight loss in older men on rates of bone loss is increased in the presence of low T levels. ${ }^{134}$ Support for this comes from another MrOS analysis showing that low free $\mathrm{T}$ is an independent predictor of low BMD and increased prevalence of fractures. ${ }^{135}$
Bariatric surgery appears to be a particularly strong risk factor for BMD loss ${ }^{136,137}$ and fractures. ${ }^{138-140} \mathrm{~A}$ 7-year prospective study after RYGB (baseline mean age $43 \pm 8$ years, BMI $42 \pm 6 \mathrm{~kg} / \mathrm{m}^{2}$ ) found continuous decline in BMD and deterioration of bone microarchitecture, as well as reduced estimated bone strength compared with baseline and 2 years postsurgery. ${ }^{137} \mathrm{~A}$ meta-analysis concluded that bariatric surgery significantly increases fracture risk. ${ }^{138}$

In contrast, long-term TTh for 6 years results in a significant progressive improvement of BMD and T-scores, while simultaneously reducing obesity markers (body weight and WC). ${ }^{94}$ Another long-term study found that TTh for 8 years significantly increased vertebral and femoral BMD, despite sub-optimal TTh dosing. ${ }^{103}$ The anabolic effect of TTh on the bone was unequivocally demonstrated in the Testosterone Trials (T-Trials). ${ }^{141}$ These findings underscore that full realization of the osteoanabolic effects of TTh can only be realized in the long term.

When given in conjunction with a diet program, TTh modulates bone remodeling markers in a way indicative of a favorable long-term effect on BMD. ${ }^{142}$ TTh is the only available treatment that results in long-term sustained weight loss combined with increased BMD. Further study is needed to find out whether this translates into a reduced incidence of fractures.

\section{Weight Loss Versus Fat Loss}

Obesity treatment interventions commonly target weight loss alone, ${ }^{26,115,143}$ without attention to effects on body composition and health outcomes. ${ }^{144-148}$ In fact, regulatory agencies require that obesity drug trials have change in body weight as the primary efficacy end-point. ${ }^{149}$ This is a problem, as a myopic focus on weight loss alone can mask important body composition improvements, such as reduction in total and/or visceral fat mass accompanied by preservation, ${ }^{44}$ or even gain in FFM. ${ }^{150}$ Further, it can lead to frustration and dropout among patients with obesity who think that weight loss is the only desirable result.

The goal of obesity treatment is to lose excess body fat mass while preserving FFM, which consists of $40-$ $68 \%$ muscle mass. ${ }^{127,151,152}$ The preservation of FFM is critical, because loss of FFM may increase risk for weight regain and increased fatness, by lowering maintenance energy requirement and triggering increased hunger/appetite. ${ }^{153}$ Further, FFM is important for maintenance of metabolic health, ${ }^{151}$ bone mass/skeletal integrity, ${ }^{154}$ and quality of life. ${ }^{155}$ Higher FFM (muscle 
mass) is associated with a significantly reduced risk of the MetS, ${ }^{156}$ nonalcoholic fatty liver disease, ${ }^{157}$ $\mathrm{T} 2 \mathrm{DM},{ }^{158}$ as well as lower mortality risk, independently of body fat mass, $\mathrm{CV}$, and metabolic risk factors. $^{159-162}$ In older age, $\geq 65$ years, loss of FFM is a particularly strong risk factor for mortality, independently of body fat. ${ }^{163}$ Hence, the preservation of FFM during weight loss is important for both successful weight loss maintenance as well as reduction of comorbidities and mortality risk.

A concern with traditional obesity treatment modalities is that they cause a significant loss of FFM. ${ }^{127}$ Currently, no guidelines are available that define how much FFM loss is excessive during or after weight loss interventions. According to the "Quarter FFM Rule," in healthy weight loss, the fraction of weight loss that can be attributed to FFM should not exceed $25 \%{ }^{164}$ Although the percentage of weight loss that constitutes FFM is influenced by variables such as physical activity, diet composition, degree of caloric restriction, etc., $25 \%$ is a reasonable reference point for examination of the degree to which different weight loss interventions achieve preservation of FFM and a healthy weight loss.

A meta-analysis of lifestyle interventions for weight loss (minimum intervention period including followup of $\geq 12$ months) found that $25 \%$ of weight loss comprises FFM. ${ }^{165}$ A systematic review found that the mean FFM loss as a percentage of weight loss after dietary and drug-based weight-loss interventions resulting in a weight loss of $>10 \mathrm{~kg}$ is $27 \%$ and $31 \%$, respectively. ${ }^{166}$ In a sex-specific body composition analysis at 1,2, and 5 years after bariatric surgery, baseline body weight and FFM in men was $137.4 \mathrm{~kg}$ and $77.8 \mathrm{~kg}$, respectively. ${ }^{167}$ At 1,2 , and 5 years postsurgery, body weight (weight loss) was $94.4 \mathrm{~kg}(-43 \mathrm{~kg}), 98.1 \mathrm{~kg}$ $(-39.3 \mathrm{~kg}$ ), and $105.4 \mathrm{~kg}(-32 \mathrm{~kg})$, and FFM (FFM loss) was $69.1 \mathrm{~kg}(-8.7 \mathrm{~kg}), 70.2(-7.6 \mathrm{~kg})$, and $69.9 \mathrm{~kg}$ $(-8.7 \mathrm{~kg})$. The percentage of weight lost as FFM was, hence, $20 \%$ at year $1,19 \%$ at year 2, and $25 \%$ at year 5. ${ }^{167}$ However, bariatric surgery can cause FFM loss as high as $53 \%$ of weight loss 2 years postsurgery. ${ }^{168} \mathrm{~A}$ head-to-head comparison showed that bariatric surgery results in a significantly greater reduction in muscle mass than diet/exercise programs after 1 year. ${ }^{169}$

\section{Effect of TTh on Body Composition During Diet-Induced Weight Loss}

Currently, there are only a few RCTs with body composition data that specifically investigated the effect of TTh in the context of weight loss in men with obesity.
A notable diet RCT by Ng Tang Fui et al. investigated whether TTh has beneficial effects on weight loss and body composition over and above caloric restriction alone. ${ }^{44}$ Men with obesity (BMI $\left.\geq 30 \mathrm{~kg} / \mathrm{m}^{2}\right)$ and low $T \leq 12 \mathrm{nmol} / \mathrm{L}$ ( $346 \mathrm{ng} / \mathrm{dL}$ ) were randomized to receive TTh with $\mathrm{T}$ undecanoate injections every 10 weeks ( $n=49$, baseline weight $118.3 \mathrm{~kg}$ ) or matching placebo ( $n=51$, baseline weight $120.7 \mathrm{~kg}$ ) for 56 weeks. Both groups underwent a very-low calorie diet during week 1 to 10 , which was followed by a weight maintenance period of 46 weeks. Subjects were advised to perform at least $30 \mathrm{~min}$ of moderate-intensity exercise each day and completed exercise questionnaires and accelerometer testing (at weeks 0,10 , and 56) to reinforce and encourage participation in exercise. After the very-low calorie diet (phase 1 , week 0 to 10 ), subjects were put on a less stringent calorie-restricted diet for the remaining 46 weeks (phase 2, week 11 to 56). At the end of the 10 -week diet phase, weight loss was $12 \mathrm{~kg}$ and $13.5 \mathrm{~kg}$ in the T-group and placebo group, respectively (difference between groups not significant). There was a trend toward a $0.4 \mathrm{~kg}$ greater reduction in body fat mass and a $0.9 \mathrm{~kg}$ smaller reduction in lean mass in the T-group. At the end of phase 2 (week 56), weight loss remained largely stable in the T-group ( $+0.6 \mathrm{~kg}, p=0.62)$, whereas there was weight regain in the placebo group $(+2.6 \mathrm{~kg}, p=0.06)$. At study end, men on TTh had, compared with placebo, lost significantly more body fat mass $(-2.9 \mathrm{~kg}$ vs. $-0.4 \mathrm{~kg}, p=0.04)$ and visceral fat $\left(-2678 \mathrm{~mm}^{2}\right.$ vs. $\left.-1099 \mathrm{~mm}^{2}, p=0.04\right)$, and regained the diet-induced loss of lean mass $(+3.4 \mathrm{~kg}$ vs. $+0.9 \mathrm{~kg}, p=0.002)$. As the combined loss of body fat and lean mass in men on placebo was similar to the amount of fat mass lost in men on TTh, there was no difference in body weight at study end. It is remarkable that men who had received TTh had a 7.3-fold greater reduction in total body fat and a 2.4-fold greater reduction in visceral fat mass than men on placebo.

A unique benefit of TTh in the context of weight loss is preservation of FFM (muscle mass). At the end of phase 1 (after 10 weeks on a very-low calorie diet), the fraction of weight loss comprising FFM was $32.5 \%$ and $35.5 \%$ in men on TTh and placebo, respectively. At study end (week 56), the fraction of weight loss comprising FFM was $5.3 \%$ in men on TTh and $36.7 \%$ in men on placebo. To the best of our knowledge, $5.3 \%$ is the smallest reduction in FFM ever reported in weight-loss trials. Support for the conclusion that TTh preserves muscle mass comes from the 
finding that men on TTh had a significantly higher appendicular lean mass and increased handgrip strength than men on placebo.

At the end of phase 1 (week 10), both groups had increased daily step count $(p<0.01)$ and activity levels $(p<0.05)$. However, at study end (week 56), daily step count was increased only in men on TTh, as was percentage of daily nonsedentary time (due to spending less time in sedentary activities and more time in light activities. Notably, the dropout rate was higher among men assigned to placebo compared with TTh. This suggests that TTh may make it easier for men with obesity to adhere to diet/exercise programs.

A likely explanation for the lack of preservation of lean mass during the initial diet phase may be the short duration of 10 weeks, as T-induced changes in lean mass or FFM typically require several months to manifest. ${ }^{170}$ It should be pointed out that the greater reduction in body fat and preservation of lean mass in the T-group occurred despite a modest increase in endogenous total and free $\mathrm{T}$ levels $(+2.9 \mathrm{nmol} / \mathrm{L}$ $[+84 \mathrm{ng} / \mathrm{dL}]$ and $+30.3 \mathrm{pmol} / \mathrm{L}[+10.5 \mathrm{pg} / \mathrm{mL}]$, respectively) in the placebo group. ${ }^{44}$ This diet-induced elevation in $\mathrm{T}$ levels is similar to what has been seen in previous weight-loss studies, ${ }^{41,171}$ and it suggests that the endogenous rise in $\mathrm{T}$ subsequent to dieting is not sufficient to prevent diet-related loss of lean mass.

The results from $\mathrm{Ng}$ Tang Fui et al. confirm findings from previous smaller studies showing that TTh combined with lifestyle modification results in better outcomes than lifestyle modification alone. In 2009, a small RCT with 16 subjects who were newly diagnosed with T2DM and MetS showed for the first time that the combination of TTh and lifestyle intervention leads to greater therapeutic improvement in glycemic control, and reverses the MetS, after 52 weeks of treatment. ${ }^{172}$ An 18-week (4.5 months) RCT in men with obesity and obstructive sleep apnea showed that the combination of TTh and lifestyle modification improved insulin sensitivity, ameliorated fatty liver, and increased muscle mass, in comparison to placebo and lifestyle modification alone. ${ }^{173}$ In elderly men (age 65-85 years), TTh for 12 weeks combined with a resistance exercise program did not have any effect on body composition compared with placebo. ${ }^{174}$ This is likely due to the short 3-month duration.

An RCT of 167 generally healthy communitydwelling older men (age 66 years) found that TTh for 12 months combined with resistance exercise training resulted in a greater reduction in fat mass by $1.2 \mathrm{~kg}$, a greater increase in FFM by $1.7 \mathrm{~kg}$, and a $0.3 \mathrm{~kg}$ greater increase in arm FFM than resistance exercise training alone. $^{175}$

An observational, parallel-arm, open-label 54-week study investigated the effect of hypocaloric diet plus exercise (DPE; $n=12$ ) or DPE plus treatment with T undecanoate injections (DPE $+\mathrm{T} ; n=12$ ), followed by 24 weeks of DPE alone in 24 men with obesity (BMI $42 \mathrm{~kg} / \mathrm{kg}^{2}$; age 54 years). ${ }^{97}$ After 54 weeks, the DPE $+\mathrm{T}$ group had improvement in epicardial fat thickness, ejection fraction, diastolic function, carotid intimamedia thickness (CIMT), and endothelial function $(p<0.01$ vs. controls). Also, hormonal (T, $p<0.0001$; $\mathrm{GH}, p<0.01$ ), metabolic (Homeostatic Model Assessment of Insulin Resistance [HOMA-IR], $p<0.01$; microalbuminuria, $p<0.01$ ), lipid (total cholesterol, $p<0.05$ ), and inflammatory (fibrinogen, $p<0.05$ ) parameters improved. After 24 weeks from T withdrawal, most parameters returned to baseline. A 33\% dropout rate was reported in the DPE group, whereas there was no dropout among men receiving TTh. ${ }^{97}$

\section{Effect of TTh on Body Composition Without Dieting}

Studies with body composition outcomes highlight the importance of looking beyond weight change when evaluating the potential clinical utility of TTh for prevention of obesity. It should be pointed out that shorterterm studies of TTh in the absence of dieting may show lack of change in body weight or even an increased body weight, but they still have beneficial effects on body composition by reducing body fat and increasing FFM.

For example, in men with normal weight and low $\mathrm{T}$ $(13.6 \mathrm{nmol} / \mathrm{L}$ or $392 \mathrm{ng} / \mathrm{dL})$, TTh for 1 year selectively reduced visceral fat accumulation without change in total body FM and increased total body FFM and total body and thigh skeletal muscle mass. ${ }^{64}$ In another study of men with obesity (BMI $40 \mathrm{~kg} / \mathrm{m}^{2}$ ) and hypogonadism $(231 \mathrm{ng} / \mathrm{dL})$, TTh for 24 weeks reduced subcutaneous fat mass by $-3.3 \mathrm{~kg}$ and increased lean mass by $3.4 \mathrm{~kg}{ }^{150}$ Despite a lack of change in body weight, there was a significant improvement in insulin sensitivity. ${ }^{150}$ In men with overweight, TTh for 6 months increased lean body mass by $3.6 \mathrm{~kg}$ while simultaneously decreasing total fat mass by $-1.2 \mathrm{~kg}$, resulting in a net gain in body weight despite a significant reduction in percent body fat. ${ }^{176}$

One RCT aimed at investigating the effect of TTh with $\mathrm{T}$ undecanoate injections versus placebo on $\mathrm{CV}$ risk factors, atherosclerosis progression, and 
body composition in a population of men with hypogonadism and MetS and T2DM. ${ }^{177}$ After 12 months, men in the T-group had a reduction in body fat percent and WC by $-18.5 \%$ and $-8.5 \mathrm{~cm}$, and an increase in FFM by $4.8 \mathrm{~kg}$, despite no change in body weight. This was accompanied by a marked improvement in insulin sensitivity (HOMA-IR, $p<0.001)$ and reduction in $\mathrm{HbA}_{1 \mathrm{c}}(p<0.01)$, high-sensitivity $\mathrm{C}$-reactive protein $(p<0.001)$, as well as CIMT $(p<0.0001)$. In contrast, no changes were seen in the placebo group. ${ }^{177}$

In 161 men with TD and baseline BMI of $26 \mathrm{~kg} / \mathrm{m}^{2}$, TTh for 52 weeks reduced body fat from $28.8 \%$ to $24.5 \% .{ }^{178}$ In a long-term follow-up of this study, body fat declined from $31.5 \%$ to $26.5 \%$ at month 24 , whereas $\mathrm{T}$ levels increased from 263 to $551 \mathrm{ng} / \mathrm{dL}$. Thereafter, there was a reduction in $\mathrm{T}$ levels, so that at month 96 the mean T level was $372 \mathrm{ng} / \mathrm{dL}$. As the $\mathrm{T}$ level declined, body fat increased, so that at the end of the study there was no difference in body fat compared with baseline. ${ }^{103}$ This underscores the importance of maintaining high enough elevations of $\mathrm{T}$ levels throughout the entire treatment period.

In contrast to RCTs of TTh in men with normal weight and overweight, which show improvement in body composition with no change or increase in body weight, ${ }^{179}$ RCTs that included mostly men with obesity show significant reduction in body weight and WC. $^{53,180,181}$ The first double-blind, placebo-controlled study conducted exclusively in men with T2DM and obesity was published in 2014. Patients $(n=211)$ were recruited from general practices for a 30-week RCT of TTh with $\mathrm{T}$ undecanoate injections, followed by 52 weeks of open-label treatment. ${ }^{180}$ After 30 weeks, there was a significant reduction in WC by $-2.5 \mathrm{~cm}$ and a small nonsignificant reduction in body weight. After 82 weeks, there was a significant weight loss of $-2.7 \mathrm{~kg}$ and reduction in $\mathrm{WC}$ by $-4.2 \mathrm{~cm}$. At both time points, there were significant improvements in $\mathrm{HbA}_{1 \mathrm{c}}$ and total cholesterol. Hypogonadism symptoms had significantly improved at week 82, but not week $30{ }^{180}$ This suggests that 30 weeks (7.5 months) is not enough for weight loss and symptomatic improvement. Further support for the importance of long-term TTh comes from a long-term follow-up of this study, which found that WC and erectile function continued to improve for 4 years with ongoing uninterrupted $\mathrm{TTh} .{ }^{53}$ Remarkably, the progressive improvement in erectile function for nearly 4 years was independent of PDE5i use. ${ }^{53}$

Another RCT of TTh in 55 men with obesity and T2DM showed that treatment with $\mathrm{T}$ undecanoate in- jections versus placebo injections for 1 year significantly reduced HOMA-IR by -4.64 versus -0.52 , $\mathrm{HbA}_{1 \mathrm{c}}(\%)$ by -0.94 versus -0.24 , fasting glucose $(\mathrm{mmol} / \mathrm{L})$ by -1.23 versus -0.13 , fasting insulin $(\mathrm{mE} / \mathrm{L})$ by -8.52 versus -0.51 and CIMT $(\mathrm{mm})$, a surrogate measure of atherosclerosis, by -0.10 versus -0.05 . $^{182}$ Endothelial function, measured by flow mediated dilatation (FMD, \%), improved by 2.40 versus -0.08 . Although the between-group difference in body weight and WC was not significant after 1 year, in a follow-up of this study, where the placebo group was switched over to treatment with $\mathrm{T}$ undecanoate injections and the $\mathrm{T}$ group continued receiving $\mathrm{T}$ undecanoate injections for a second year, there was a significant reduction in body weight and. ${ }^{181}$ In men who had been receiving $\mathrm{T}$ undecanoate injections for 2 years (which increased total $\mathrm{T}$ to $23.5 \mathrm{nmol} / \mathrm{L}$ and free $\mathrm{T}$ (calculated) to $594 \mathrm{pmol} / \mathrm{L}$ ), there was a significant reduction in $\mathrm{WC}$ by $3.51 \mathrm{~cm}$ and $\mathrm{BMI}$ by $-1.6 \mathrm{~kg} / \mathrm{m}^{2}{ }^{181}$ This was accompanied by further improvement in insulin resistance/glucose control, lipids, atherosclerosis, and endothelial function; HOMA-IR ( -5.94 , final reading 5.51), fasting glucose $(-1.83 \mathrm{mmol} / \mathrm{L}$, final reading $8.23 \mathrm{mmol} / \mathrm{L})$, $\mathrm{HbA}_{1 \mathrm{c}}(-1.51 \%$, final reading $6.6 \%)$, total cholesterol $(-0.97 \mathrm{nmol} / \mathrm{L}$, final reading $4.34 \mathrm{nmol} / \mathrm{L})$, LDL $(-0.40 \mathrm{nmol} / \mathrm{L}$, final reading $2.39 \mathrm{nmol} / \mathrm{L})$, $\mathrm{HDL}$ $(+0.15 \mathrm{nmol} / \mathrm{L}$, final reading $1.15 \mathrm{nmol} / \mathrm{L})$, triglycerides $(-0.99 \mathrm{nmol} / \mathrm{L}$, final reading $1.86 \mathrm{nmol} / \mathrm{L})$, nonHDL $(1.12 \mathrm{nmol} / \mathrm{L}$, final reading $3.19 \mathrm{nmol} / \mathrm{L})$, FMD $(+2.46 \%$, final reading 7.14$)$, and CIMT $(-0.14 \mathrm{~mm}$, final reading 0.73). It should be pointed out that these beneficial effects of TTh were achieved without any diet or exercise intervention. This RCT with follow-up shows that TTh for at least 2 years may be needed in some populations of men to achieve significant improvements in body weight, WC, insulin resistance/ glucose control, lipids, atherosclerosis, and endothelial function.

More studies of TTh with long-term body composition data are needed to elucidate how the effects of $\mathrm{T}$ treatment on fat loss, FFM gain, and metabolic outcomes are influenced by TTh dose, treatment duration, as well as diet and exercise (or lack thereof), in men with obesity, the MetS and/or T2DM.

\section{Reduction in CV Events and Mortality with Long-Term TTh in Daily Clinical Practice}

Considering that obesity is a strong CV risk factor, and the widespread misperception about TTh and CV risk, 
it is important to examine long-term RWE data of TTh in men with obesity. In one RWE study, 77 men with obesity, hypogonadism, and a history of CVD were treated with $\mathrm{T}$ undecanoate injections for up to 8 years. $^{88}$ No patient suffered a major adverse CV event during the entire 8 year-long observation time. It was concluded that TTh in men with a history of CVD may be effective as an add-on treatment for secondary prevention of $\mathrm{CV}$ events. ${ }^{88}$

In the first RWE study analysis that included a control group, 360 men with obesity and TD received T undecanoate injections for up to 10 years. ${ }^{89}$ This TTh group was compared with a control group of 296 men who had opted to not receive TTh. There were 26 cases of nonfatal MI and 30 cases of nonfatal stroke in the control group and none in the TTh group. In the nontreated control group, there were 21 deaths, 19 of which were due to CV events (5 MI, 4 stroke, 7 heart failure, 2 thromboembolisms, 1 lung embolism). In the TTh group, there were only 2 deaths, and none was related to $\mathrm{CV}$ events (one was due to postsurgical thromboembolism and the other due to traffic accident). The estimated reduction in mortality for the TTh compared with the control group was between $66 \%$ and $92 \% .{ }^{89}$ This is the first large RWE study showing a significant reduction in hard clinical end-points with long-term TTh.

In the prediabetes RWE study described earlier, the incidence of nonfatal MI and mortality was $0.4 \%$ and $7.4 \%$ in the TTh group, and $5.7 \%$ and $16.1 \%$ in the control group, respectively. ${ }^{54}$ Similarly, in the T2DM remission RWE study, there was no MI or stroke in T-treated men. Among untreated men, 31\% had MI and 25\% stroke. Mortality rate was $7 \%$ in T-treated men and $29 \%$ in untreated men. ${ }^{92}$

The effect on hard clinical end-points after treatment with $\mathrm{T}$ undecanoate injections for up to 11 years in men with different weight classes, compared with untreated men, is illustrated in Figure $2 .{ }^{42}$ Remarkably, there were no cases of MI nor stroke in any of the TTh groups.

Adverse events in men with different weight classes during treatment with $\mathrm{T}$ undecanoate injections for up to 11 years could be compared with untreated (control) patients. ${ }^{42}$

In men with various degrees of $\mathrm{ED}$, TTh was given to 412 patients for up to 12 years, whereas 393 served as a control group. ${ }^{93}$ In the TTh groups, no MI nor stroke occurred during the entire observation period (Fig. 3). In the untreated groups, MI and stroke oc- curred in $18.9 \%$ and $14.9 \%$ of patients with moderate/ severe $\mathrm{ED}$, respectively, and $16 \%$ and $15.3 \%$ in patients with no/mild ED. In the TTh groups, death from all causes occurred in $6.5 \%$ and $2.3 \%$ of men with no/mild ED and moderate/severe ED, respectively. In the untreated groups, death occurred in $14.6 \%$ and $21.3 \%$ of men with no/mild ED and moderate/severe ED, respectively. In the T-treated groups, PCa occurred in $0 \%$ and $2.3 \%$ of men with no/mild ED and moderate/severe $\mathrm{ED}$, respectively. In the untreated groups, $\mathrm{PCa}$ occurred in $6.9 \%$ and $6.8 \%$ of men with no/mild ED and moderate/severe ED, respectively.

\section{Discussion and Conclusion}

$\mathrm{T}$ is a key metabolic hormone with well-documented effects on body fat, muscle mass, and the skeleton. ${ }^{36,141,170,179,183,184}$ TD is particularly common in men with obesity. Because $\mathrm{T}$ is a key metabolic hormone, achieving and maintaining weight loss in men who have TD is extremely difficult. Numerous studies have shown that adding TTh to lifestyle interventions increases fat loss while preserving or increasing FFM. $^{97,172,173,175}$

Loss of FFM and regain of body fat over time is a major drawback of diet and/or drug-based obesity treatment interventions. ${ }^{127}$ Preservation of FFM during weight loss is critical, as reduction in FFM may counteract the beneficial health effects of weight loss, ${ }^{185}$ as well as increase risk for weight regain. ${ }^{153}$ In studies of diet/exercise interventions, around $25-35 \%$ of weight loss comprises FFM. After bariatric surgery, 20-50\% of weight loss comprises FFM. ${ }^{167,168}$ The RCT data show that dieting men who receive placebo lose both body fat and lean mass, whereas weight loss in dieting men receiving TTh was almost exclusively body fat. ${ }^{44}$ After 1 year of reduced caloric intake, the fraction of weight loss comprising FFM was $36.7 \%$ in men on placebo but only $5.3 \%$ in men on TTh. This suggests that TTh augments diet-induced loss of body fat and prevents loss of FFM. The mechanisms underlying the anabolic effect of TTh on muscle during diet interventions are starting to get elucidated, and it has been concluded that TTh is a viable strategy for preserving muscle mass during caloric restriction. ${ }^{186}$

Although RCTs are considered to provide the highest quality evidence, efficacy of an intervention under controlled conditions is not synonymous with effectiveness, that is, intervention outcomes in "realworld" conditions. ${ }^{187-189}$ Because obesity is a chronic condition that is greatly influenced by lifestyle, 


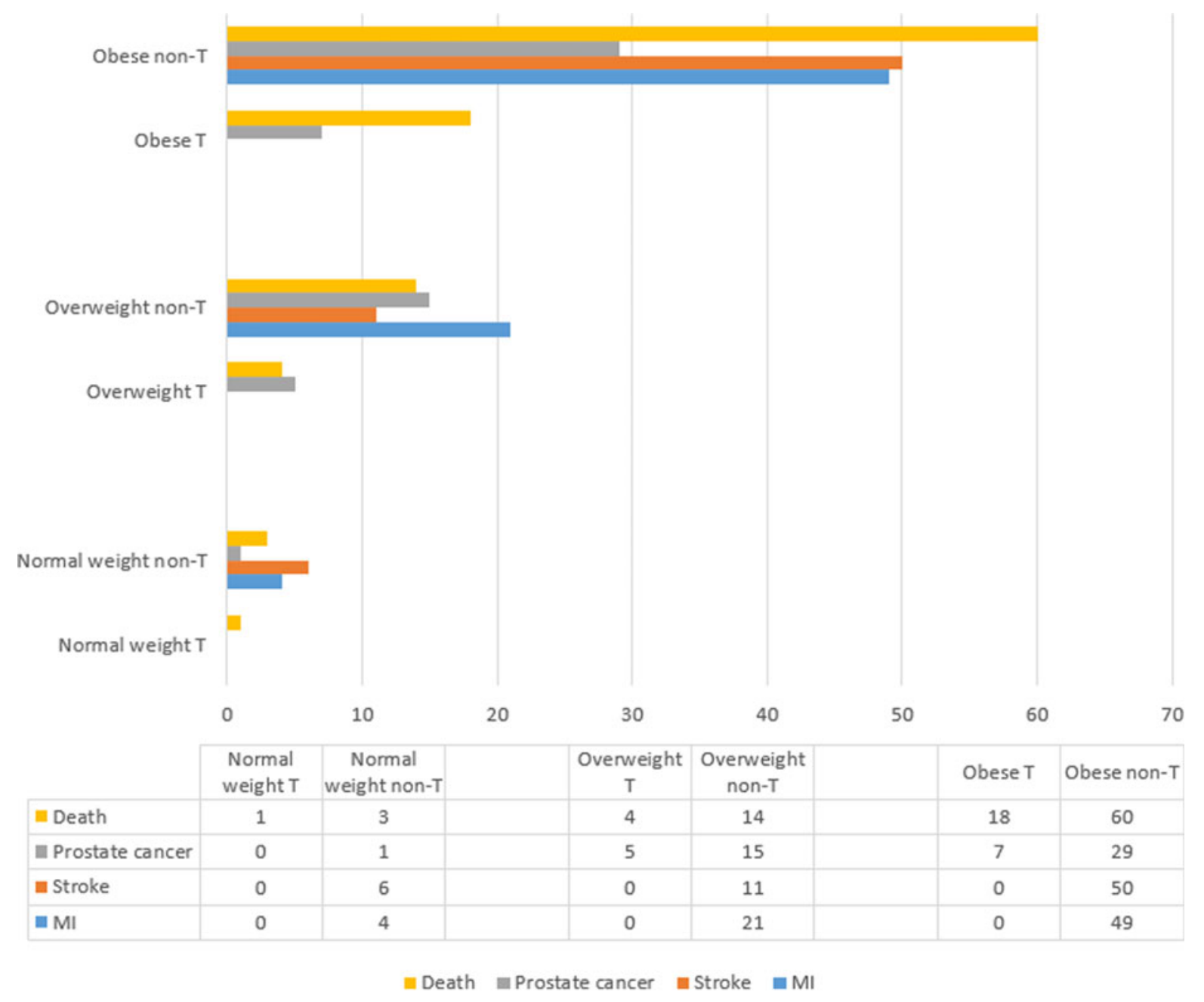

FIG. 2. Incidence of death, nonfatal myocardial infarction, nonfatal stroke, and prostate cancer in men with TD and normal weight, overweight, and obesity after treatment with $T$ undecanoate injections (T), compared with untreated men (non-T). Ml, myocardial infarction. Data from: Saad et al. ${ }^{42}$

evidence for how weight loss/maintenance interventions work in daily living conditions in the long term is essential.

Long-term RWE studies of men with TD and obesity who receive TTh in routine clinical practice show large amounts of weight loss that is progressive and sustained over time, with no plateau reported for up to 11 years. ${ }^{42}$ This is opposite to the experience with obesity drugs, which have declining drug efficacy/effectiveness over time, often culminating in a weight-loss plateau within $\sim 1$ year. ${ }^{190}$ Further, because $\mathrm{T}$ is a key metabolic hormone, by correcting TD, TTh creates a metabolic environment that facilitates fat loss and long-term maintenance of an improved body composition.
The prevalence of severe obesity (BMI $\geq 35 \mathrm{~kg} / \mathrm{m}^{2}$ ) is rising at an alarming pace; by 2030 , it is projected to affect one in four adults. ${ }^{191,192}$ Considering that conventional weight-loss interventions (diet, exercise, drugs) have minimal impact in patients with severe obesity, ${ }^{193}$ it is particularly noteworthy that long-term TTh for up to 8 years reduced BMI from 37.3 to 29.5 in men with grade II obesity (BMI 35-39.9) and from 41.9 to 32.4 in men with grade III obesity. ${ }^{55}$ This suggests that TTh also offers significant clinical value for men with more severe obesity.

The RWE studies have additionally provided valuable insight about the consequences of untreated TD. ${ }^{42}$ Men with TD who do not receive TTh have an 


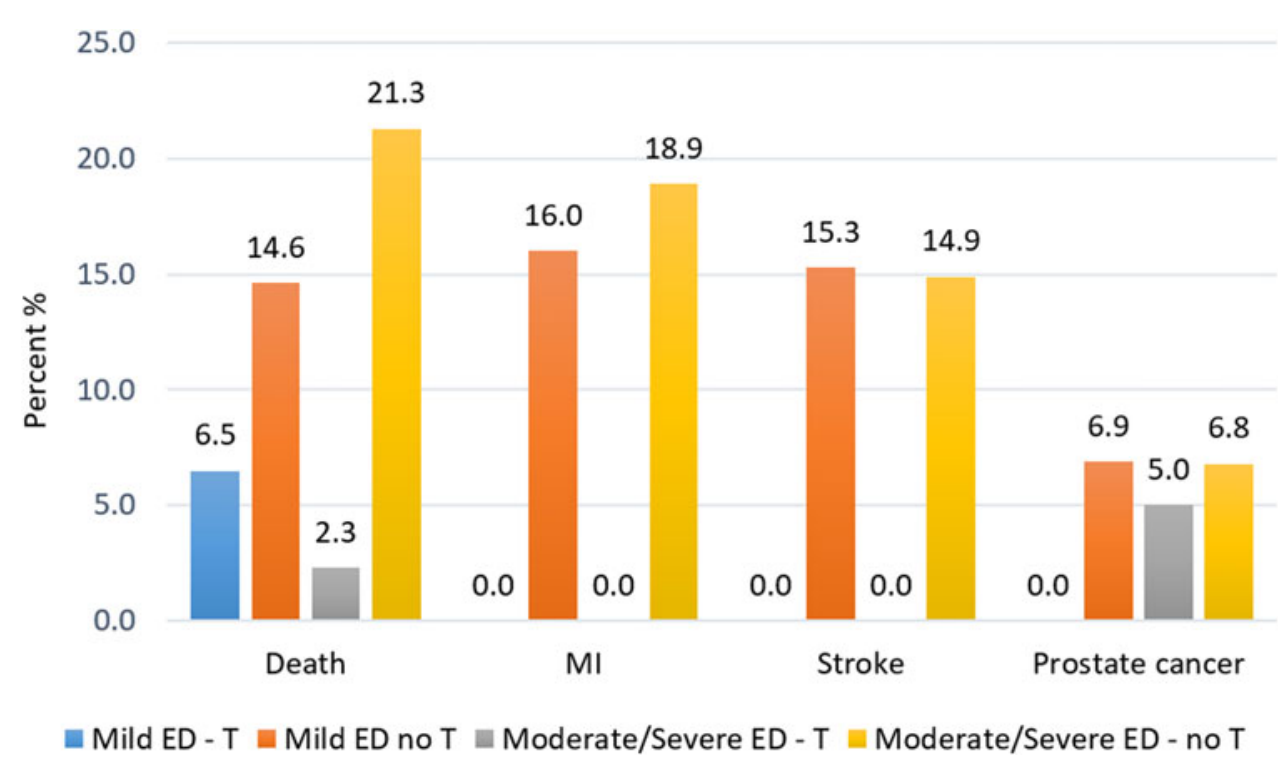

FIG. 3. Adverse events (\%) in patients with no/mild and moderate/severe ED during treatment with $T$ undecanoate injections for up to 12 years $(T)$, compared with untreated (control) patients (no T). ED, erectile dysfunction; T, testosterone. Data from: Saad et al. ${ }^{93}$

increase in body weight and WC over time, regardless of baseline bodyweight. It is remarkable that in men with obesity, long-term TTh results in a weight loss of similar magnitude as that achieved with bariatric surgery. Change in body weight and BMI are the most frequently used measures to evaluate bariatric surgery outcomes. However, body weight-based metrics do not provide information about change in body composition (body fat and lean mass), which is what ultimately matters in terms of chronic disease risk, particularly T2DM and CVD. Bariatric surgery results in a large amount of weight loss and better weight loss maintenance compared with diet/exercise interventions; however, this is followed by a disproportional regain of body fat during the second and third year after bariatric surgery. ${ }^{194,195}$ A sex-specific analysis showed that men have increases in all adipose tissue depots between 12 and 24 months postsurgery with weight regain. ${ }^{196}$ In parallel with the significant postsurgery body fat rebound, there is progressive worsening of lipid parameters, suggesting that the adverse switch in the change in body composition between the first and third year may underlie the observed recurrence of CV risk factors over time. ${ }^{194,195}$ In stark contrast, the weight loss and reduction in WC observed in RWE studies of long-term TTh is progressive over time and accompanied by marked improvement in glycemic control and lipid profile. Support for the beneficial effects of TTh on body composition comes from 36-month RCTs showing progressive reduction in body fat percent with TTh versus placebo. ${ }^{56,197}$ However, a prerequisite for achievement of body fat loss with TTh is adequate dosing of TTh and adherence to treatment, so that a sufficient $\mathrm{T}$ level elevation is reached and maintained in the long term. ${ }^{103}$

In addition to increased fat loss and preservation of FFM, TTh may make it easier for men to adhere to diet/exercise programs. ${ }^{44}$ Support for this comes from experimental studies showing that TTh increases spontaneous physical activity by enhancing CNS sensitivity to dopamine. ${ }^{198}$ Previous studies have shown that TTh consistently improves mood and feelings of energy, and it reduces fatigue ${ }^{199-204}$; this, in turn, may bolster motivation and the ability to adhere to diet/exercise programs. ${ }^{172,205,206}$

Effective intervention to curb the rapidly growing obesity epidemic, which is affecting men of all ages, is urgently needed. Long-term "real-life" studies provide compelling evidence that TTh offers significant clinical utility in the treatment of men with obesity, as well as in the prevention of obesity development, in men with TD. ${ }^{42,55,87,93}$ This is accompanied by T2DM remis$\operatorname{sion}^{92}$ and a significant reduction in T2DM incidence, ${ }^{54} \mathrm{MI}$, stroke, PCa, and mortality. ${ }^{54,88,89,92,93}$ Because obesity is a gateway to ill health, ${ }^{207}$ especially 
T2DM and CVD, a large-scale initiative for widespread implementation of TTh, as part of medical care for men with obesity, is highly warranted.

\section{Author Disclosure Statement}

F. Saad is a former employee of Bayer AG and now a consultant to Bayer AG. M. Caliber is an independent medical writer.

\section{Funding Information}

No funding was received for this article.

\section{References}

1. Di Angelantonio E, Bhupathiraju Sh N, Wormser D, et al. Body-mass index and all-cause mortality: Individual-participant-data meta-analysis of 239 prospective studies in four continents. Lancet. 2016;388(10046) 776-786.

2. Afshin A, Forouzanfar MH, Reitsma MB, et al. Health effects of overweight and obesity in 195 countries over 25 years. N Engl J Med. 2017;377(1):13-27.

3. Kivimäki M, Kuosma E, Ferrie JE, et al. Overweight, obesity, and risk of cardiometabolic multimorbidity: Pooled analysis of individual-level data for 120813 adults from 16 cohort studies from the USA and Europe. Lancet Public Health. 2017;2(6):e277-e285.

4. GBD 2017 Causes of Death Collaborators. Global, regional, and nationa age-sex-specific mortality for 282 causes of death in 195 countries and territories, 1980-2017: A systematic analysis for the Global Burden of Disease Study 2017. Lancet. 2018;392(10159):1736-1788.

5. Hales CM, Fryar CD, Carroll MD, Freedman DS, Ogden CL. Trends in obesity and severe obesity prevalence in US youth and adults by sex and age, 2007-2008 to 2015-2016. JAMA. 2018;319(16):1723-1725.

6. Han TS, Correa E, Lean ME, et al. Changes in prevalence of obesity and high waist circumference over four years across European regions: The European male ageing study (EMAS). Endocrine. 2017;55(2):456-469.

7. Pischon $\mathrm{T}$, Boeing $\mathrm{H}, \mathrm{Hoffmann} \mathrm{K}$, et al. General and abdominal adiposity and risk of death in Europe. N Engl J Med. 2008;359(20):2105-2120.

8. Després JP. Excess visceral adipose tissue/ectopic fat the missing link in the obesity paradox? J Am Coll Cardiol. 2011;57(19):1887-1889.

9. Cerhan JR, Moore SC, Jacobs EJ, et al. A pooled analysis of waist circumference and mortality in 650,000 adults. Mayo Clin Proc. 2014; 89(3):335-345.

10. Song $X$, Jousilahti $P$, Stehouwer $C D$, et al. Cardiovascular and all-cause mortality in relation to various anthropometric measures of obesity in Europeans. Nutr Metab Cardiovasc Dis. 2015;25(3):295-304.

11. Jacobs EJ, Newton CC, Wang Y, et al. Waist circumference and all-cause mortality in a large US cohort. Arch Intern Med. 2010;170(15):1293-1301.

12. Adair T, Lopez AD. The role of overweight and obesity in adverse cardiovascular disease mortality trends: An analysis of multiple cause of death data from Australia and the USA. BMC Med. 2020;18(1):199.

13. Sattar N. Gender aspects in type 2 diabetes mellitus and cardiometabolic risk. Best Pract Res Clin Endocrinol Metab. 2013;27(4):501-507.

14. Dai $H$, Alsalhe TA, Chalghaf N, Riccò $M$, Bragazzi NL, Wu J. The global burden of disease attributable to high body mass index in 195 countries and territories, 1990-2017: An analysis of the Global Burden of Disease Study. PLoS Med. 2020;17(7):e1003198.

15. Lovejoy JC, Sainsbury A. Sex differences in obesity and the regulation of energy homeostasis. Obes Rev. 2009;10(2):154-167.

16. Faulkner JL, Belin de Chantemèle EJ. Sex hormones, aging and cardiometabolic syndrome. Biol Sex Differ. 2019;10(1):30.

17. Bhaskaran K, Dos-Santos-Silva I, Leon DA, Douglas IJ, Smeeth L. Association of BMI with overall and cause-specific mortality: A population-based cohort study of $3 \cdot 6$ million adults in the UK. Lancet Diabetes Endocrinol. 2018;6(12):944-953.

18. Vidra N, Trias-Llimos S, Janssen F. Impact of obesity on life expectancy among different European countries: Secondary analysis of populationlevel data over the 1975-2012 period. BMJ Open. 2019;9(7):e028086.
19. Seidell JC, Verschuren WMM, van Leer EM, Kromhout D. Overweight underweight, and mortality: A prospective study of 48287 men and women. Arch Intern Med. 1996;156(9):958-963.

20. Kramer FM, Jeffery RW, Forster JL, Snell MK. Long-term follow-up of behavioral treatment for obesity: Patterns of weight regain among men and women. Int J Obes. 1989:13(2):123-136.

21. Pownall HJ, Bray GA, Wagenknecht LE, et al. Changes in body composition over 8 years in a randomized trial of a lifestyle intervention: The look AHEAD study. Obesity (Silver Spring). 2015;23(3):565-572.

22. Navarro G, Allard C, Xu W, Mauvais-Jarvis F. The role of androgens in metabolism, obesity, and diabetes in males and females. Obesity (Silver Spring). 2015;23(4):713-719.

23. Archibald D, Douglas $F$, Hoddinott $P$, et al. A qualitative evidence synthesis on the management of male obesity. BMJ Open. 2015;5(10): e008372.

24. Men's Health Forum (UK). How to make weight loss services work for men. Available at https://www.menshealthforum.org.uk/sites/default/ files/pdf/how_to_weight_final_Ir_1.pdf. Accessed May 10, 2020.

25. Bray GA, Heisel WE, Afshin A, et al. The science of obesity management: An endocrine society scientific statement. Endocr Rev. 2018;39(2): 79-132.

26. Garvey WT, Mechanick Jl, Brett EM, et al. American Association of Clinical Endocrinologists and American College of Endocrinology comprehensive clinical practice guidelines for medical care of patients with obesity. Endocr Pract. 2016;22 Suppl 3:1-203.

27. Jensen MD, Ryan DH, Apovian CM, et al. 2013 AHA/ACC/TOS guideline for the management of overweight and obesity in adults: A report of the American College of Cardiology/American Heart Association Task Force on practice guidelines and the obesity society. J Am Coll Cardiol. 2014;63(25 Pt B):2985-3023.

28. Carmienke $\mathrm{S}$, Freitag $\mathrm{MH}$, Pischon $\mathrm{T}$, et al. General and abdominal obesity parameters and their combination in relation to mortality: A systematic review and meta-regression analysis. Eur J Clin Nutr. 2013 67(6):573-585.

29. Rohrmann S, Shiels MS, Lopez DS, et al. Body fatness and sex steroid hormone concentrations in US men: Results from NHANES III. Cancer Causes Control. 2011;22(8):1141-1151.

30. Alberti KG, Eckel RH, Grundy SM, et al. Harmonizing the metabolic syndrome: A joint interim statement of the International Diabetes Federation Task Force on Epidemiology and Prevention; National Heart, Lung, and Blood Institute; American Heart Association; World Heart Federation; International Atherosclerosis Society; and International Association for the Study of Obesity. Circulation. 2009;120(16):16401645.

31. Sahakyan KR, Somers VK, Rodriguez-Escudero JP, et al. Normal-weight central obesity: Implications for total and cardiovascular mortality. Ann Intern Med. 2015;163(11):827-835.

32. Mainous AG, 3rd, Tanner RJ, Jo A, Anton SD. Prevalence of prediabetes and abdominal obesity among healthy-weight adults: 18-year trend. Ann Fam Med. 2016;14(4):304-310.

33. Mulligan AA, Lentjes MAH, Luben RN, Wareham NJ, Khaw KT. Changes in waist circumference and risk of all-cause and CVD mortality: Results from the European Prospective Investigation into Cancer in Norfolk (EPIC-Norfolk) cohort study. BMC Cardiovasc Disord. 2019;19(1):238.

34. Song $X$, Jousilahti $P$, Stehouwer $C D$, et al. Comparison of various surrogate obesity indicators as predictors of cardiovascular mortality in four European populations. Eur J Clin Nutr. 2013;67(12):12981302.

35. Molina-Vega M, Munoz-Garach A, Damas-Fuentes M, Fernandez-Garcia JC, Tinahones FJ. Secondary male hypogonadism: A prevalent but overlooked comorbidity of obesity. Asian J Androl. 2018;20(6):531-538.

36. Kelly DM, Jones TH. Testosterone and obesity. Obes Rev. 2015;16(7): 581-606.

37. Travison TG, Araujo AB, Kupelian V, O'Donnell AB, McKinlay JB. The relative contributions of aging, health, and lifestyle factors to serum testosterone decline in men. J Clin Endocrinol Metab. 2007:92(2): 549-555

38. Wu FC, Tajar A, Pye SR, et al. Hypothalamic-pituitary-testicular axis disruptions in older men are differentially linked to age and modifiable risk factors: The European Male Aging Study. J Clin Endocrinol Metab. 2008;93(7):2737-2745. 
39. Wu FC, Tajar A, Beynon JM, et al. Identification of late-onset hypogonadism in middle-aged and elderly men. N Engl J Med. 2010; 363(2):123-135

40. Camacho EM, Huhtaniemi IT, O'Neill TW, et al. Age-associated changes in hypothalamic-pituitary-testicular function in middle-aged and older men are modified by weight change and lifestyle factors: Longitudinal results from the European Male Ageing Study. Eur J Endocrinol. 2013; 168(3):445-455.

41. Corona G, Rastrelli G, Monami M, et al. Body weight loss reverts obesityassociated hypogonadotropic hypogonadism: A systematic review and meta-analysis. Eur J Endocrinol. 2013;168(6):829-843.

42. Saad F, Doros G, Haider KS, Haider A. Differential effects of 11 years of long-term injectable testosterone undecanoate therapy on anthropometric and metabolic parameters in hypogonadal men with normal weight, overweight and obesity in comparison with untreated controls: Real-world data from a controlled registry study. Int J Obes. 2020;44(6): 1264-1278.

43. Eriksson J, Haring R, Grarup N, et al. Causal relationship between obesity and serum testosterone status in men: A bi-directional mendelian randomization analysis. PLoS One. 2017;12(4):e0176277.

44. Ng Tang Fui M, Prendergast LA, Dupuis $P$, et al. Effects of testosterone treatment on body fat and lean mass in obese men on a hypocaloric diet: A randomised controlled trial. BMC Med. 2016;14(1):153.

45. Ng Tang Fui M, Hoermann R, Prendergast LA, Zajac JD, Grossmann M. Symptomatic response to testosterone treatment in dieting obese men with low testosterone levels in a randomized, placebo-controlled clinical trial. Int J Obes (Lond). 2017;41(3):420-426.

46. Ng Tang Fui M, Hoermann R, Zajac JD, Grossmann M. The effects of testosterone on body composition in obese men are not sustained after cessation of testosterone treatment. Clin Endocrinol (Oxf). 2017;87(4): 336-343.

47. Thirumalai A, Rubinow KB, Cooper LA, et al. Dose-response effects of sex hormone concentrations on body composition and adipokines in medically castrated healthy men administered graded doses of testosterone gel. Clin Endocrinol (Oxf). 2017;87(1):59-67.

48. Finkelstein JS, Lee $H$, Burnett-Bowie SA, et al. Gonadal steroids and body composition, strength, and sexual function in men. N Engl J Med. 2013; 369(11):1011-1022.

49. Hamilton EJ, Gianatti E, Strauss BJ, et al. Increase in visceral and subcutaneous abdominal fat in men with prostate cancer treated with androgen deprivation therapy. Clin Endocrinol (Oxf). 2011;74(3): 377-383.

50. Chasland LC, Knuiman MW, Divitini ML, et al. Higher circulating androgens and higher physical activity levels are associated with less central adiposity and lower risk of cardiovascular death in older men. Clin Endocrinol (Oxf). 2019;90(2):375-383.

51. Khaw KT, Barrett-Connor E. Lower endogenous androgens predict central adiposity in men. Ann Epidemiol. 1992;2(5):675-682.

52. Tsai EC, Boyko EJ, Leonetti DL, Fujimoto WY. Low serum testosterone level as a predictor of increased visceral fat in Japanese-American men. Int J Obes Relat Metab Disord. 2000;24(4):485-491.

53. Hackett G, Cole N, Mulay A, Strange RC, Ramachandran S. Long-term testosterone therapy in type 2 diabetes is associated with decreasing waist circumference and improving erectile function. World J Mens Health. 2020;38(1):68-77.

54. Yassin A, Haider A, Haider KS, et al. Testosterone therapy in men with hypogonadism prevents progression from prediabetes to type 2 diabetes: Eight-year data from a registry study. Diabetes Care. 2019;6(42): 1104-1111.

55. Saad F, Yassin A, Doros G, Haider A. Effects of long-term treatment with testosterone on weight and waist size in 411 hypogonadal men with obesity classes I-III: Observational data from two registry studies. Int J Obes (Lond). 2016;40(1):162-170.

56. Page ST, Amory JK, Bowman FD, et al. Exogenous testosterone (T) alone or with finasteride increases physical performance, grip strength, and lean body mass in older men with low serum T. J Clin Endocrinol Metab. 2005;90(3):1502-1510.

57. Snyder PJ, Peachey H, Hannoush P, et al. Effect of testosterone treatment on body composition and muscle strength in men over 65 years of age. J Clin Endocrinol Metab. 1999;84(8):2647-2653.

58. Kenny AM, Prestwood KM, Gruman CA, Marcello KM, Raisz LG. Effects of transdermal testosterone on bone and muscle in older men with low bioavailable testosterone levels. J Gerontol A Biol Sci Med Sci. 2001; 56(5):M266-M272.

59. Wittert GA, Chapman IM, Haren MT, Mackintosh S, Coates P, Morley JE. Oral testosterone supplementation increases muscle and decreases fat mass in healthy elderly males with low-normal gonadal status. J Gerontol A Biol Sci Med Sci. 2003;58(7):618-625.

60. Wang C, Swerdloff RS, Iranmanesh A, et al. Transdermal testosterone gel improves sexual function, mood, muscle strength, and body composition parameters in hypogonadal men. J Clin Endocrinol Metab. 2000; 85(8):2839-2853.

61. Sattler F, He J, Chukwuneke J, et al. Testosterone supplementation improves carbohydrate and lipid metabolism in some older men with abdominal obesity. J Gerontol Geriatr Res. 2014;3(3):1000159.

62. Marin P, Holmang S, Gustafsson $C$, et al. Androgen treatment of abdominally obese men. Obes Res. 1993;1(4):245-251.

63. Marin $\mathrm{P}$, Holmang $\mathrm{S}$, Jonsson $\mathrm{L}$, et al. The effects of testosterone treatment on body composition and metabolism in middle-aged obese men Int J Obes Relat Metab Disord. 1992;16(12):991-997.

64. Allan CA, Strauss BJ, Burger HG, Forbes EA, McLachlan RI. Testosterone therapy prevents gain in visceral adipose tissue and loss of skeletal muscle in nonobese aging men. J Clin Endocrinol Metab. 2008;93(1): 139-146.

65. Hackett G, Kirby M, Edwards D, et al. British society for sexual medicine guidelines on adult testosterone deficiency, with statements for UK practice. J Sex Med. 2017;14(12):1504-1523.

66. Harman SM, Metter EJ, Tobin JD, Pearson J, Blackman MR. Longitudinal effects of aging on serum total and free testosterone levels in healthy men. Baltimore Longitudinal Study of Aging. J Clin Endocrinol Metab. 2001;86(2):724-731.

67. Feldman HA, Longcope C, Derby CA, et al. Age trends in the level of serum testosterone and other hormones in middle-aged men: Longitudinal results from the Massachusetts male aging study. J Clin Endocrinol Metab. 2002;87(2):589-598.

68. Lapauw B, Goemaere S, Zmierczak H, et al. The decline of serum testosterone levels in community-dwelling men over 70 years of age: Descriptive data and predictors of longitudinal changes. Eur J Endocrinol. 2008;159(4):459-468.

69. Mohr BA, Guay AT, O'Donnell AB, McKinlay JB. Normal, bound and nonbound testosterone levels in normally ageing men: Results from the Massachusetts Male Ageing Study. Clin Endocrinol (Oxf). 2005;62(1): 64-73.

70. Haring $\mathrm{R}$, Ittermann $\mathrm{T}$, Volzke $\mathrm{H}$, et al. Prevalence, incidence and risk factors of testosterone deficiency in a population-based cohort of men: Results from the study of health in Pomerania. Aging Male. 2010;13(4): 247-257.

71. Liu PY, Beilin J, Meier C, et al. Age-related changes in serum testosterone and sex hormone binding globulin in Australian men: Longitudinal analyses of two geographically separate regional cohorts. J Clin Endocrinol Metab. 2007;92(9):3599-3603.

72. Couillard C, Gagnon J, Bergeron J, et al. Contribution of body fatness and adipose tissue distribution to the age variation in plasma steroid hormone concentrations in men: The HERITAGE Family Study. J Clin Endocrinol Metab. 2000;85(3):1026-1031.

73. Hales CM, Carroll MD, Fryar CD, Ogden CL. Prevalence of obesity among adults and youth: United States, 2015-2016. NCHS Data Brief. 2017(288) $1-8$.

74. van Hulsteijn LT, Pasquali $R$, Casanueva $F$, et al. Prevalence of endocrine disorders in obese patients: Systematic review and meta-analysis. Eur J Endocrinol. 2020;182(1):11-21.

75. Gapstur SM, Gann PH, Kopp P, Colangelo L, Longcope C, Liu K. Serum androgen concentrations in young men: A longitudinal analysis of associations with age, obesity, and race. The CARDIA male hormone study. Cancer Epidemiol Biomarkers Prev. 2002;11(10 Pt 1):10411047.

76. Gapstur SM, Kopp P, Gann PH, Chiu BC, Colangelo LA, Liu K. Changes in $\mathrm{BMI}$ modulate age-associated changes in sex hormone binding globulin and total testosterone, but not bioavailable testosterone in young adult men: The CARDIA Male Hormone Study. Int J Obes (Lond). 2007;31(4): 685-691.

77. Dhindsa S, Ghanim H, Batra M, Dandona P. Hypogonadotropic hypogonadism in men with diabesity. Diabetes Care. 2018;41(7):15161525 
78. Chandel A, Dhindsa S, Topiwala S, Chaudhuri A, Dandona $P$. Testosterone concentration in young patients with diabetes. Diabetes Care. 2008;31(10):2013-2017.

79. Mogri M, Dhindsa S, Quattrin T, Ghanim H, Dandona P. Testosterone concentrations in young pubertal and post-pubertal obese males. Clin Endocrinol (Oxf). 2013;78(4):593-599.

80. Molina-Vega M, Asenjo-Plaza M, García-Ruiz MC, et al. Cross-sectional, primary care-based study of the prevalence of hypoandrogenemia in nondiabetic young men with obesity. Obesity (Silver Spring). 2019; 27(10):1584-1590.

81. Pellitero S, Olaizola I, Alastrue A, et al. Hypogonadotropic hypogonadism in morbidly obese males is reversed after bariatric surgery. Obes Surg. 2012;22(12):1835-1842.

82. Mulligan T, Frick MF, Zuraw QC, Stemhagen A, McWhirter C. Prevalence of hypogonadism in males aged at least 45 years: The HIM study. Int J Clin Pract. 2006;60(7):762-769.

83. Calderón B, Gómez-Martín JM, Vega-Piñero B, et al. Prevalence of male secondary hypogonadism in moderate to severe obesity and its relationship with insulin resistance and excess body weight. Andrology. 2016;4(1):62-67.

84. Dhindsa S, Miller MG, McWhirter CL, et al. Testosterone concentrations in diabetic and nondiabetic obese men. Diabetes Care. 2010;33(6): 1186-1192.

85. Trabert B, Graubard BI, Nyante SJ, et al. Relationship of sex steroid hormones with body size and with body composition measured by dual-energy X-ray absorptiometry in US men. Cancer Causes Control. 2012;23(12):1881-1891.

86. Francomano D, Lenzi A, Aversa A. Effects of five-year treatment with testosterone undecanoate on metabolic and hormonal parameters in ageing men with metabolic syndrome. Int J Endocrinol. 2014;2014: 527470.

87. Yassin AA, Nettleship J, Almehmadi Y, Salman M, Saad F. Effects of continuous long-term testosterone therapy (TTh) on anthropometric, endocrine and metabolic parameters for up to 10 years in 115 hypogonadal elderly men: Real-life experience from an observational registry study. Andrologia. 2016;48(7):793-799.

88. Haider A, Yassin A, Haider KS, Doros G, Saad F, Rosano GM. Men with testosterone deficiency and a history of cardiovascular diseases benefit from long-term testosterone therapy: Observational, real-life data from a registry study. Vasc Health Risk Manag. 2016;12:251-261.

89. Traish AM, Haider A, Haider KS, Doros G, Saad F. Long-term testosterone therapy improves cardiometabolic function and reduces risk of cardiovascular disease in men with hypogonadism: A real-life observational registry study setting comparing treated and untreated (control) groups. J Cardiovasc Pharmacol Ther. 2017;22(5):414-433.

90. Zitzmann M, Traish A, Kliesch S. Long-term treatment of hypogonadal men: Results from a 9-year-registry J Urol. 2017;197:e1220-e1221.

91. Saad F, Doros G, Haider KS, Haider A. Hypogonadal men with moderate-to-severe lower urinary tract symptoms have a more severe cardiometabolic risk profile and benefit more from testosterone therapy than men with mild lower urinary tract symptoms. Investig Clin Urol. 2018;59(6):399-409.

92. Haider KS, Haider A, Saad F, et al. Remission of type 2 diabetes following long-term treatment with injectable testosterone undecanoate in patients with hypogonadism and type 2 diabetes: 11-year data from a real-world registry study. Diabetes Obes Metab. 2020 [Epub ahead of print]; DOI: 10.1111/dom.14122.

93. Saad F, Caliber M, Doros G, Haider KS, Haider A. Long-term treatment with testosterone undecanoate injections in men with hypogonadism alleviates erectile dysfunction and reduces risk of major adverse cardiovascular events, prostate cancer, and mortality. Aging Male. 2020 23(1):81-92.

94. Haider A, Meergans U, Traish A, et al. Progressive improvement of T-scores in men with osteoporosis and subnormal serum testosterone levels upon treatment with testosterone over six years. Int J Endocrinol. 2014;2014:496948.

95. Haider A, Zitzmann M, Doros G, Isbarn H, Hammerer P, Yassin A. Incidence of prostate cancer in hypogonadal men receiving testosterone therapy: Observations from five year-median follow-up of three registries. J Urol. 2015;193(1):80-86.

96. O'Connell MD, Roberts SA, Srinivas-Shankar U, et al. Do the effects of testosterone on muscle strength, physical function, body composition, and quality of life persist six months after treatment in intermediate-frail and frail elderly men? J Clin Endocrinol Metab. 2011;96(2):454-458.

97. Francomano D, Bruzziches R, Barbaro G, Lenzi A, Aversa A. Effects of testosterone undecanoate replacement and withdrawal on cardio-metabolic, hormonal and body composition outcomes in severely obese hypogonadal men: A pilot study. J Endocrinol Invest. 2014;37(4):401-411.

98. Yassin A, Almehmadi Y, Saad F, Doros G, Gooren L. Effects of intermission and resumption of long-term testosterone replacement therapy on body weight and metabolic parameters in hypogonadal in middle-aged and elderly men. Clin Endocrinol (Oxf). 2016;84(1):107-114.

99. Yassin A, Nettleship JE, Talib RA, Almehmadi Y, Doros G. Effects of tes tosterone replacement therapy withdrawal and re-treatment in hypogonadal elderly men upon obesity, voiding function and prostate safety parameters. Aging Male. 2016;19(1):64-69.

100. Morgunov LY, Denisova IA, Rozhkova TI, Stakhovskaya LV, Skvortsova VI. Hypogonadism and its treatment following ischaemic stroke in men with type 2 diabetes mellitus. Aging Male. 2020;23(1):71-80.

101. Hackett $G$, Cole N, Bhartia $M$, et al. The response to testosterone undecanoate in men with type 2 diabetes is dependent on achieving threshold serum levels (the BLAST study). Int J Clin Pract. 2014;68(2): 203-215.

102. Sattler F, Bhasin S, He J, et al. Testosterone threshold levels and lean tissue mass targets needed to enhance skeletal muscle strength and function: The HORMA trial. J Gerontol A Biol Sci Med Sci. 2011; 66(1):122-129.

103. Permpongkosol S, Khupulsup K, Leelaphiwat S, Pavavattananusorn S, Thongpradit S, Petchthong T. Effects of 8-year treatment of long-acting testosterone undecanoate on metabolic parameters, urinary symptoms, bone mineral density, and sexual function in men with late-onset hypogonadism. J Sex Med. 2016;13(8):1199-1211.

104. Sharma R, Oni OA, Gupta K, et al. Normalization of testosterone level is associated with reduced incidence of myocardial infarction and mortality in men. Eur Heart J. 2015;36(40):2706-2715.

105. Sharma R, Oni OA, Gupta K, et al. Normalization of testosterone levels after testosterone replacement therapy is associated with decreased incidence of atrial fibrillation. J Am Heart Assoc. 2017;6(5): e004880.

106. Oni OA, Dehkordi SHH, Jazayeri MA, et al. Relation of testosterone normalization to mortality and myocardial infarction in men with previous myocardial infarction. Am J Cardiol. 2019;124(8):1171-1178.

107. Saad F, Aversa A, Isidori AM, Zafalon L, Zitzmann M, Gooren L. Onset of effects of testosterone treatment and time span until maximum effects are achieved. Eur J Endocrinol. 2011;165(5):675-685.

108. Caliber M, Hackett G. Important lessons about testosterone therapyweight loss vs. testosterone therapy for symptom resolution, classical vs. functional hypogonadism, and shortterm vs. lifelong testosterone therapy. Aging Male. 2019 [Epub ahead of print]; DOI: 10.1080/13685538.2018.1549211.

109. Franz MJ, VanWormer JJ, Crain AL, et al. Weight-loss outcomes: A systematic review and meta-analysis of weight-loss clinical trials with a minimum 1-year follow-up. J Am Diet Assoc. 2007;107(10): 1755-1767.

110. Douketis JD, Macie C, Thabane L, Williamson DF. Systematic review of long-term weight loss studies in obese adults: Clinical significance and applicability to clinical practice. Int J Obes (Lond). 2005;29(10): 1153-1167.

111. Anderson JW, Vichitbandra S, Qian W, Kryscio RJ. Long-term weight maintenance after an intensive weight-loss program. J Am Coll Nutr. 1999;18(6):620-627.

112. Curioni CC, Lourenço PM. Long-term weight loss after diet and exercise: A systematic review. Int J Obes (Lond). 2005;29(10):1168-1174.

113. Anderson JW, Konz EC, Frederich RC, Wood CL. Long-term weight-loss maintenance: A meta-analysis of US studies. Am J Clin Nutr. 2001;74(5): 579-584.

114. Yanovski SZ, Yanovski JA. Long-term drug treatment for obesity: A systematic and clinical review. JAMA. 2014;311(1):74-86

115. Khera R, Murad MH, Chandar AK, et al. Association of pharmacological treatments for obesity with weight loss and adverse events: A systematic review and meta-analysis. JAMA. 2016;315(22):2424-2434.

116. Look Ahead Research Group. Long-term effects of a lifestyle intervention on weight and cardiovascular risk factors in individuals with type 2 
diabetes mellitus: Four-year results of the Look AHEAD trial. Arch Intern Med. 2010;170(17):1566-1575.

117. MacLean PS, Wing RR, Davidson T, et al. NIH working group report: Innovative research to improve maintenance of weight loss. Obesity (Silver Spring). 2015;23(1):7-15.

118. Fischer $M$, Oberänder $N$, Weimann A. Four main barriers to weight loss maintenance? A quantitative analysis of difficulties experienced by obese patients after successful weight reduction. Eur J Clin Nutr. 2020; 74(8):1192-1200.

119. Nordmo M, Danielsen YS, Nordmo M. The challenge of keeping it off, a descriptive systematic review of high-quality, follow-up studies of obesity treatments. Obes Rev. 2020;21(1):e12949.

120. Mathus-Vliegen EM. Long-term maintenance of weight loss with sibutramine in a GP setting following a specialist guided very-lowcalorie diet: A double-blind, placebo-controlled, parallel group study. Eur J Clin Nutr. 2005;59 Suppl 1:S31-S38; discussion S39.

121. Funk MD, Lee M, Vidoni ML, Reininger BM. Weight loss and weight gain among participants in a community-based weight loss challenge. BMC Obes. 2019;6:2.

122. Sjöström L. Review of the key results from the Swedish Obese Subjects (SOS) trial-A prospective controlled intervention study of bariatric surgery. J Intern Med. 2013;273(3):219-234.

123. O'Brien PE, Hindle A, Brennan L, et al. Long-term outcomes after bariatric surgery: A systematic review and meta-analysis of weight loss at 10 or more years for all bariatric procedures and a single-centre review of 20-year outcomes after adjustable gastric banding. Obes Surg. 2019; 29(1):3-14.

124. Courcoulas AP, King WC, Belle SH, et al. Seven-year weight trajectories and health outcomes in the longitudinal assessment of bariatric surgery (LABS) study. JAMA Surg. 2018;153(5):427-434.

125. Jans A, Näslund I, Ottosson J, Szabo E, Näslund E, Stenberg E. Duration of type 2 diabetes and remission rates after bariatric surgery in Sweden 2007-2015: A registry-based cohort study. PLoS Med. 2019;16(11): e1002985.

126. Pessoa BM, Browning MG, Mazzini GS, et al. Factors mediating type 2 diabetes remission and relapse after gastric bypass surgery. J Am Coll Surg. 2020;230(1):7-16.

127. Marks BL, Rippe JM. The importance of fat free mass maintenance in weight loss programmes. Sports Med. 1996;22(5):273-281.

128. Soltani S, Hunter GR, Kazemi A, Shab-Bidar S. The effects of weight loss approaches on bone mineral density in adults: A systematic review and meta-analysis of randomized controlled trials. Osteoporos Int. 2016; 27(9):2655-2671.

129. Ensrud KE, Fullman RL, Barrett-Connor E, et al. Voluntary weight reduction in older men increases hip bone loss: The osteoporotic fractures in men study. J Clin Endocrinol Metab. 2005;90(4):1998-2004.

130. Guney E, Kisakol G, Ozgen G, Yilmaz C, Yilmaz R, Kabalak T. Effect of weight loss on bone metabolism: Comparison of vertical banded gastroplasty and medical intervention. Obes Surg. 2003;13(3):383388

131. Waters DL, Vawter R, Qualls C, Chode S, Armamento-Villareal R, Villareal DT. Long-term maintenance of weight loss after lifestyle intervention in frail, obese older adults. J Nutr Health Aging. 2013;17(1):3-7.

132. Langlois JA, Visser M, Davidovic LS, Maggi S, Li G, Harris TB. Hip fracture risk in older white men is associated with change in body weight from age 50 years to old age. Arch Intern Med. 1998;158(9): 990-996.

133. Komorita $Y$, Iwase $M$, Fujii $H$, et al. Impact of body weight loss from maximum weight on fragility bone fractures in Japanese patients with type 2 diabetes: The Fukuoka Diabetes Registry. Diabetes Care. 2018; 41(5):1061.

134. Ensrud KE, Lewis CE, Lambert LC, et al. Endogenous sex steroids, weight change and rates of hip bone loss in older men: The MrOS study. Osteoporos Int. 2006;17(9):1329-1336.

135. Mellström $D$, Johnell $O$, Ljunggren $O$, et al. Free testosterone is an independent predictor of BMD and prevalent fractures in elderly men: MrOS Sweden. J Bone Miner Res. 2006;21(4):529-535

136. Maghrabi AH, Wolski K, Abood B, et al. Two-year outcomes on bone density and fracture incidence in patients with T2DM randomized to bariatric surgery versus intensive medical therapy. Obesity (Silver Spring). 2015;23(12):2344-2348.
137. Hansen S, Jørgensen NR, Hermann AP, Støving RK. Continuous decline in bone mineral density and deterioration of bone microarchitecture 7 years after Roux-en- $Y$ gastric bypass surgery. Eur J Endocrinol. 2020; 182(3):303-311.

138. Ablett $A D$, Boyle $B R$, Avenell A. Fractures in adults after weight loss from bariatric surgery and weight management programs for obesity: Systematic review and meta-analysis. Obes Surg. 2019;29(4):13271342.

139. Zhang Q, Chen Y, Li J, et al. A meta-analysis of the effects of bariatric surgery on fracture risk. Obes Rev. 2018;19(5):728-736.

140. Khalid SI, Omotosho PA, Spagnoli A, Torquati A. Association of bariatric surgery with risk of fracture in patients with severe obesity. JAMA Netw Open. 2020;3(6):e207419.

141. Snyder PJ, Kopperdahl DL, Stephens-Shields AJ, et al. Effect of testosterone treatment on volumetric bone density and strength in older men with low testosterone: A controlled clinical trial. JAMA Intern Med. 2017;177(4):471-479.

142. Ng Tang Fui M, Hoermann R, Nolan B, Clarke M, Zajac JD, Grossmann M. Effect of testosterone treatment on bone remodelling markers and mineral density in obese dieting men in a randomized clinical trial. Sci Rep. 2018;8(1):9099.

143. Jensen MD, Ryan DH, Apovian CM, et al. 2013 AHA/ACC/TOS guideline for the management of overweight and obesity in adults: A report of the American College of Cardiology/American Heart Association Task Force on Practice Guidelines and The Obesity Society. Circulation. 2014; 129(25 Suppl 2):S102-S138.

144. Gadde KM, Allison DB, Ryan DH, et al. Effects of low-dose, controlledrelease, phentermine plus topiramate combination on weight and associated comorbidities in overweight and obese adults (CONQUER): A randomised, placebo-controlled, phase 3 trial. Lancet. 2011;377(9774): $1341-1352$

145. Pi-Sunyer $\mathrm{X}$, Astrup A, Fujioka K, et al. A randomized, controlled trial of $3.0 \mathrm{mg}$ of liraglutide in weight management. N Engl J Med. 2015; 373(1):11-22.

146. Smith SR, Weissman NJ, Anderson CM, et al. Multicenter, placebocontrolled trial of lorcaserin for weight management. N Engl J Med. 2010;363(3):245-256.

147. Greenway FL, Fujioka K, Plodkowski RA, et al. Effect of naltrexone plus bupropion on weight loss in overweight and obese adults (COR-I): A multicentre, randomised, double-blind, placebo-controlled, phase 3 trial. Lancet. 2010:376(9741):595-605.

148. Stubbs RJ, Morris L, Pallister C, Horgan G, Lavin JH. Weight outcomes audit in 1.3 million adults during their first 3 months' attendance in a commercial weight management programme. BMC Public Health. 2015; 15:882.

149. Colman E. Food and Drug Administration's obesity drug guidance document: A short history. Circulation. 2012;125(17):21562164.

150. Dhindsa S, Ghanim $H$, Batra $M$, et al. Insulin resistance and inflammation in hypogonadotropic hypogonadism and their reduction after testosterone replacement in men with type 2 diabetes. Diabetes Care. 2016; 39(1):82-91

151. Wolfe RR. The underappreciated role of muscle in health and disease. Am J Clin Nutr. 2006;84(3):475-482.

152. Prior BM, Modlesky CM, Evans EM, et al. Muscularity and the density of the fat-free mass in athletes. J Appl Physiol (1985). 2001;90(4): 1523-1531.

153. Dulloo AG, Jacquet J, Miles-Chan JL, Schutz Y. Passive and active roles of fat-free mass in the control of energy intake and body composition regulation. Eur J Clin Nutr. 2017;71(3):353-357.

154. Bano G, Pigozzo S, Piovesan $F$, et al. Influence of serum 25 hydroxyvitamin D levels, fat-free mass, and fat mass on bone density, geometry and strength, in healthy young and elderly adults. Exp Gerontol. 2018;113:193-198.

155. Trombetti A, Reid KF, Hars M, et al. Age-associated declines in muscle mass, strength, power, and physical performance: Impact on fear of falling and quality of life. Osteoporos Int. 2016;27(2): 463-471.

156. Park BS, Yoon JS. Relative skeletal muscle mass is associated with development of metabolic syndrome. Diabetes Metab J. 2013;37(6): 458-464. 
157. Kim G, Lee SE, Lee YB, et al. Relationship between relative skeletal muscle mass and nonalcoholic fatty liver disease: A 7-year longitudinal study. Hepatology. 2018;68(5):1755-1768.

158. Kalyani RR, Metter EJ, Xue QL, et al. The relationship of lean body mass with aging to the development of diabetes. J Endocr Soc. 2020;4(7): bvaa043.

159. Srikanthan $P$, Karlamangla AS. Muscle mass index as a predictor of longevity in older adults. Am J Med. 2014;127(6):547-553.

160. Wannamethee SG, Shaper AG, Lennon L, Whincup PH. Decreased muscle mass and increased central adiposity are independently related to mortality in older men. Am J Clin Nutr. 2007;86(5):13391346.

161. Bigaard J, Frederiksen K, Tjonneland A, et al. Body fat and fat-free mass and all-cause mortality. Obes Res. 2004;12(7):1042-1049.

162. Chuang SY, Chang HY, Lee MS, Chia-Yu Chen R, Pan WH. Skeletal muscle mass and risk of death in an elderly population. Nutr Metab Cardiovasc Dis. 2014;24(7):784-791.

163. Graf CE, Herrmann FR, Spoerri A, et al. Impact of body composition changes on risk of all-cause mortality in older adults. Clin Nutr. 2016; 35(6):1499-1505.

164. Heymsfield SB, Gonzalez MC, Shen W, Redman L, Thomas D. Weight loss composition is one-fourth fat-free mass: A critical review and critique of this widely cited rule. Obes Rev. 2014;15(4):310-321.

165. Schwingshackl L, Dias S, Hoffmann G. Impact of long-term lifestyle programmes on weight loss and cardiovascular risk factors in overweight/obese participants: A systematic review and network metaanalysis. Syst Rev. 2014;3:130.

166. Chaston TB, Dixon JB, O'Brien PE. Changes in fat-free mass during significant weight loss: A systematic review. Int J Obes (Lond). 2007;31(5): 743-750.

167. Davidson LE, Yu W, Goodpaster BH, et al. Fat-free mass and skeletal muscle mass five years after bariatric surgery. Obesity (Silver Spring). 2018;26(7):1130-1136.

168. Valera-Mora ME, Simeoni B, Gagliardi L, et al. Predictors of weight loss and reversal of comorbidities in malabsorptive bariatric surgery. Am J Clin Nutr. 2005;81(6):1292-1297.

169. Friedrich $A E$, Damms-Machado $A$, Meile $T$, et al. Laparoscopic sleeve gastrectomy compared to a multidisciplinary weight loss program for obesity-effects on body composition and protein status. Obes Surg. 2013;23(12):1957-1965.

170. Skinner JW, Otzel DM, Bowser A, et al. Muscular responses to testosterone replacement vary by administration route: A systematic review and meta-analysis. J Cachexia Sarcopenia Muscle. 2018;9(3): 465-481.

171. Niskanen $L$, Laaksonen DE, Punnonen K, Mustajoki P, Kaukua J, Rissanen A. Changes in sex hormone-binding globulin and testosterone during weight loss and weight maintenance in abdominally obese men with the metabolic syndrome. Diabetes Obes Metab. 2004;6(3): 208-215.

172. Heufelder AE, Saad F, Bunck MC, Gooren L. Fifty-two-week treatment with diet and exercise plus transdermal testosterone reverses the metabolic syndrome and improves glycemic control in men with newly diagnosed type 2 diabetes and subnormal plasma testosterone. J Androl. 2009;30(6):726-733.

173. Hoyos CM, Yee BJ, Phillips CL, Machan EA, Grunstein RR, Liu PY. Body compositional and cardiometabolic effects of testosterone therapy in obese men with severe obstructive sleep apnoea: A randomised placebo-controlled trial. Eur J Endocrinol. 2012;167(4):531-541.

174. Katznelson L, Robinson MW, Coyle CL, Lee H, Farrell CE. Effects of modest testosterone supplementation and exercise for 12 weeks on body composition and quality of life in elderly men. Eur J Endocrinol. 2006;155(6):867-875.

175. Hildreth KL, Barry DW, Moreau KL, et al. Effects of testosterone and progressive resistance exercise in healthy, highly functioning older men with low-normal testosterone levels. J Clin Endocrinol Metab. 2013; 98(5):1891-1900.

176. Glintborg D, Vaegter HB, Christensen LL, et al. Testosterone replacement therapy of opioid-induced male hypogonadism improved body composition but not pain perception: A double-blind, randomized, and placebo-controlled trial. Eur J Endocrinol. 2020;182(6):539-548.

177. Aversa A, Bruzziches R, Francomano D, et al. Effects of testosterone undecanoate on cardiovascular risk factors and atherosclerosis in middle-aged men with late-onset hypogonadism and metabolic syndrome: Results from a 24-month, randomized, double-blind, placebo-controlled study. J Sex Med. 2010;7(10):3495-3503.

178. Permpongkosol S, Tantirangsee N, Ratana-olarn K. Treatment of 161 men with symptomatic late onset hypogonadism with long-acting parenteral testosterone undecanoate: Effects on body composition, lipids, and psychosexual complaints. J Sex Med. 2010;7(11):3765-3774.

179. Corona G, Giagulli VA, Maseroli E, et al. Testosterone supplementation and body composition: Results from a meta-analysis study. Eur J Endocrinol. 2016;174(3):R99-R116.

180. Hackett G, Cole N, Bhartia M, Kennedy D, Raju J, Wilkinson $P$. Testosterone replacement therapy improves metabolic parameters in hypogonadal men with type 2 diabetes but not in men with coexisting depression: The BLAST study. J Sex Med. 2014;11(3):840-856.

181. Groti Antonič K, Antonič B, Žuran I, Pfeifer M. Testosterone treatment longer than 1 year shows more effects on functional hypogonadism and related metabolic, vascular, diabetic and obesity parameters (results of the 2-year clinical trial). Aging Male. 2020 [Epub ahead of print]; DOI: 10.1080/13685538.2020.1793132.

182. Groti K, Zuran I, Antonic B, Forsnaric L, Pfeifer M. The impact of testosterone replacement therapy on glycemic control, vascular function, and components of the metabolic syndrome in obese hypogonadal men with type 2 diabetes. Aging Male. 2018;21(3):158-169.

183. Kelly DM, Jones TH. Testosterone: A metabolic hormone in health and disease. J Endocrinol. 2013;217(3):R25-R45.

184. Corona G, Giagulli VA, Maseroli E, et al. Testosterone supplementation and body composition: Results from a meta-analysis of observational studies. J Endocrinol Invest. 2016;39(9):967-981.

185. Sørensen TIA, Frederiksen P, Heitmann BL. Levels and changes in body mass index decomposed into fat and fat-free mass index: Relation to long-term all-cause mortality in the general population. Int J Obes (Lond). 2020 [Epub ahead of print]; DOI: 10.1038/s41366-0200613-8.

186. Howard EE, Margolis LM, Berryman CE, et al. Testosterone supplementation up-regulates androgen receptor expression and translational capacity during severe energy deficit. Am J Physiol Endocrinol Metab. 2020 [Epub ahead of print]; DOI: 10.1152/ajpendo .00157.2020.

187. Singal AG, Higgins PD, Waljee AK. A primer on effectiveness and efficacy trials. Clin Transl Gastroenterol. 2014;5(1):e45.

188. Cohen AT, Goto S, Schreiber K, Torp-Pedersen C. Why do we need observational studies of everyday patients in the real-life setting? Eur Heart J Suppl. 2015;17(suppl D):D2-D8.

189. Cox JL, Pieper K. Harnessing the power of real-life data. Eur Heart J Suppl. 2015;17(suppl_D):D9-D14.

190. Hall KD, Sanghvi A, Göbel B. Proportional Feedback Control of Energy Intake During Obesity Pharmacotherapy. Obesity (Silver Spring). 2017; 25(12):2088-2091.

191. Ward ZJ, Bleich SN, Cradock AL, et al. Projected U.S. state-level prevalence of adult obesity and severe obesity. N Engl J Med. 2019;381(25) 2440-2450.

192. Williamson K, Nimegeer A, Lean M. Rising prevalence of BMI $\geq 40 \mathrm{~kg} / \mathrm{m}(2)$ : A high-demand epidemic needing better documentation. Obes Rev. 2020;21(4):e12986.

193. Fildes A, Charlton J, Rudisill C, Littlejohns P, Prevost AT, Gulliford MC. Probability of an obese person attaining normal body weight: Cohort study using electronic health records. Am J Public Health. 2015;105(9): e54-e59.

194. Gómez-Ambrosi J, Andrada P, Valentí V, et al. Dissociation of body mass index, excess weight loss and body fat percentage trajectories after 3 years of gastric bypass: Relationship with metabolic outcomes. Int J Obes (Lond). 2017;41(9):1379-1387.

195. Sherf-Dagan S, Zelber-Sagi S, Buch A, et al. Prospective longitudinal trends in body composition and clinical outcomes 3 years following sleeve gastrectomy. Obes Surg. 2019;29(12):3833-3841.

196. Toro-Ramos T, Goodpaster BH, Janumala I, et al. Continued loss in visceral and intermuscular adipose tissue in weight-stable women following bariatric surgery. Obesity (Silver Spring). 2015;23(1):62-69.

197. Wang C, Cunningham G, Dobs A, et al. Long-term testosterone gel (AndroGel) treatment maintains beneficial effects on sexual function and mood, lean and fat mass, and bone mineral density in hypogonadal men. J Clin Endocrinol Metab. 2004;89(5):2085-2098. 
198. Jardi F, Laurent MR, Kim N, et al. Testosterone boosts physical activity in male mice via dopaminergic pathways. Sci Rep. 2018;8(1):957.

199. Amanatkar HR, Chibnall JT, Seo BW, Manepalli JN, Grossberg GT. Impact of exogenous testosterone on mood: A systematic review and metaanalysis of randomized placebo-controlled trials. Ann Clin Psychiatry. 2014;26(1):19-32.

200. Spitzer M, Basaria S, Travison TG, Davda MN, DeRogatis L, Bhasin S. The effect of testosterone on mood and well-being in men with erectile dysfunction in a randomized, placebo-controlled trial. Andrology. 2013; 1(3):475-482.

201. Wang C, Alexander G, Berman N, et al. Testosterone replacement therapy improves mood in hypogonadal men-A clinical research center study. J Clin Endocrinol Metab. 1996;81(10):3578-3583.

202. Jockenhovel F, Minnemann T, Schubert M, et al. Comparison of longacting testosterone undecanoate formulation versus testosterone enanthate on sexual function and mood in hypogonadal men. Eur J Endocrinol. 2009;160(5):815-819.

203. Jockenhovel F, Minnemann T, Schubert M, et al. Timetable of effects of testosterone administration to hypogonadal men on variables of sex and mood. Aging Male. 2009;12(4):113-118.

204. O'Connor DB, Archer J, Wu FC. Effects of testosterone on mood, aggression, and sexual behavior in young men: A double-blind, placebo-controlled, cross-over study. J Clin Endocrinol Metab. 2004;89(6):2837-2845.

205. Saad F, Aversa A, Isidori AM, Gooren LJ. Testosterone as potential effective therapy in treatment of obesity in men with testosterone deficiency: A review. Curr Diabetes Rev. 2012;8(2):131-143.

206. Kalinchenko SY, Tishova YA, Mskhalaya GJ, Gooren LJ, Giltay EJ, Saad F. Effects of testosterone supplementation on markers of the metabolic syndrome and inflammation in hypogonadal men with the metabolic syndrome: The double-blinded placebo-controlled Moscow study. Clin Endocrinol (Oxf). 2010;73(5):602-612.

207. Frühbeck G, Toplak H, Woodward E, Yumuk V, Maislos M, Oppert JM. Obesity: The gateway to ill health-An EASO position statement on a rising public health, clinical and scientific challenge in Europe. Obesity facts. 2013;6(2):117-120.

Cite this article as: Caliber M, Saad F (2020) Testosterone therapy for prevention and treatment of obesity in men. Androgens: Clinical Research and Therapeutics 1.1, 40-61, DOI: 10.1089/andro.2020.0010.

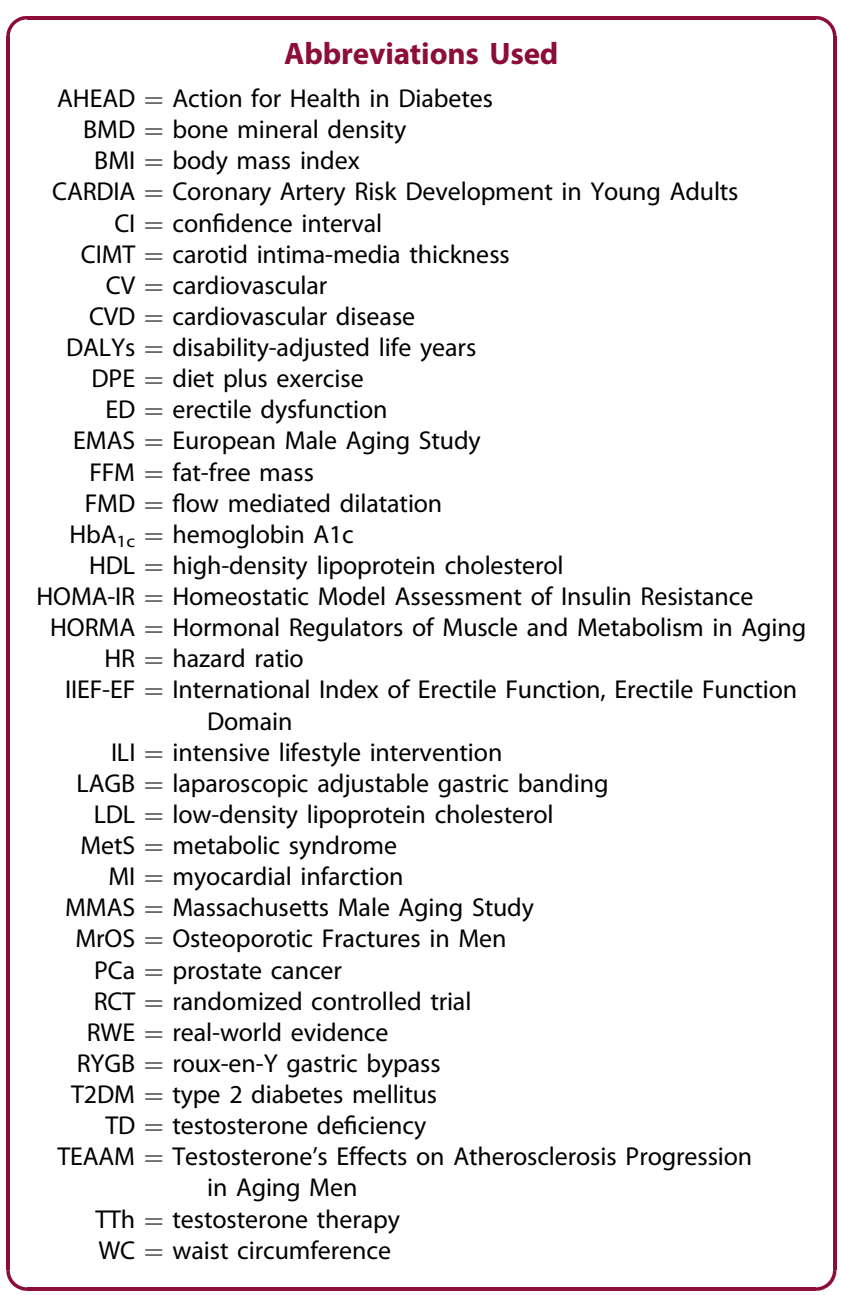

Publish in Androgens: Clinical Research and Therapeutics 